Chapter 6

\title{
Energy Storage: Battery Materials and Architectures at the Nanoscale
}

\author{
James F. Rohan, Maksudul Hasan, Sanjay Patil, \\ Declan P. Casey and Tomás Clancy \\ Additional information is available at the end of the chapter
}

http://dx.doi.org/10.5772/57139

\section{Introduction}

\subsection{Energy storage}

The intermittent nature of energy harvesting technologies and the low power delivery capability necessitates the integration of energy storage in the overall system design. A means of storing the energy produced in periods of high availability for use in periods of limited harvesting is essential. Not only is storage a major factor in the efficient use of harvested energy but it is also needed on a wide variety of time scales - seconds, minutes, hours, days - reflecting the nature of the intermittency of these sources. Correspondingly, a variety of storage technologies with different storage capabilities and response times are available.

The main storage options appropriate to ICT zero power devices are:

Batteries: Batteries are electrochemical devices using chemical reactions to generate power.

Hydrogen: Requires hydrogen production, compression, storage and power generation through fuel cells

Super-capacitors and Ultra-capacitors: Energy is stored as accumulated charge.

Batteries and hydrogen are capable of operation over the widest range of energy and power densities and thus application areas. This chapter will focus on the battery energy storage options as the most developed option with the potential for further improvements and applications in ICT devices.

Batteries are electrochemical devices that store electrical energy by directly converting it to a chemical form. Examples include lead acid, nickel-cadmium, nickel-metal-hydride, lithium- 
ion, sodium-sulphur, metal-air and flow batteries. The history of battery commercialisation is represented in figure 1, which shows the energy density per unit volume and weight for the most common rechargeable battery systems. It can be seen that the progression has been to lighter, more energy dense systems using less harmful chemicals and a greater cycling efficiency.

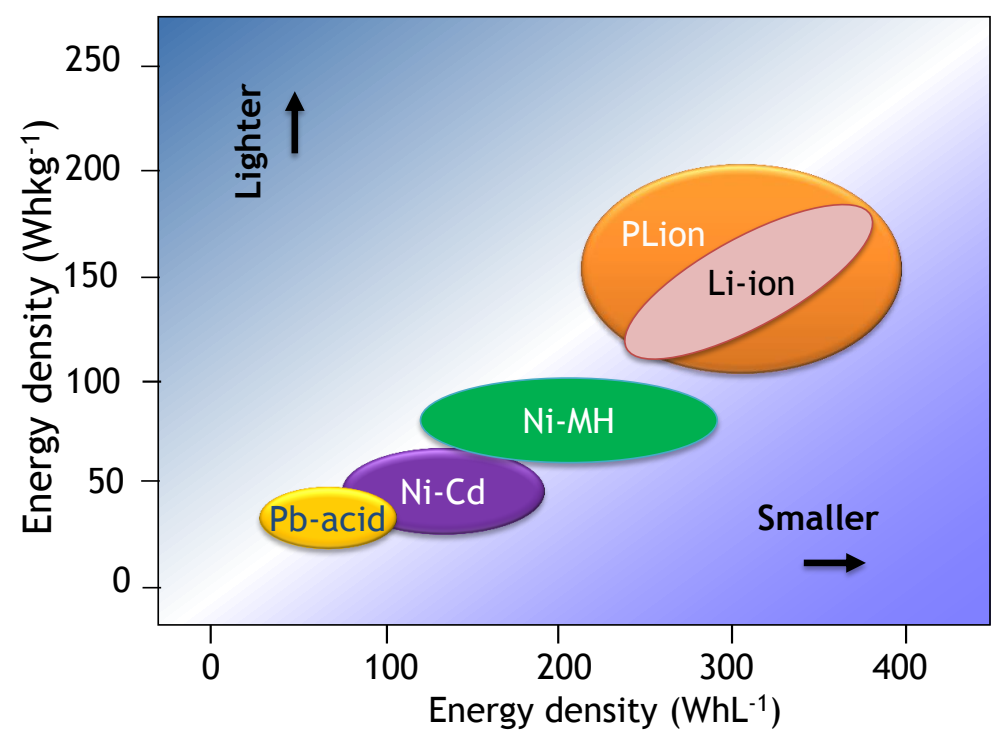

Figure 1. Commercial evolution of rechargeable batteries to higher energy density.

\subsection{Theoretical potential, capacity and energy of batteries}

The amounts of electric energy per mass or volume that a battery can deliver depends on the chemical energy stored within the electrodes. During discharge a redox reaction occurs, which gives a change in the Gibbs free energy $(\Delta G)$ of the system. High energy conversion efficiency from chemical to electrical within the cells is desirable. However, the energy available is lower than the stored chemical energy, due to polarisation of the electrodes. [1] There are mainly two types of polarisations, the activation polarisation required to drive an electrochemical reaction and secondly, the concentration polarisation due to the differences in concentration between the reactants and products at the electrode surface and in the bulk of solution due to masstransfer. The polarisation decreases the total available energy from the cell, which is lost in the form of heat. The activation and concentration polarisation can be calculated if electrochemical parameters and mass-transfer data are measurable. However, this is practically rather difficult to measure due to the complicated architecture of the electrodes.

The electrodes are normally made of composite active materials with bindera and conductivity and performance improving additives. Another key factor is the internal resistance of the cell 
which also contributes to the current drain capability and overall performance of the battery. The internal resistance causes a voltage drop during the operation, generally referred to as ohmic polarisation and its magnitude is proportional to the current delivered. Ohm's law applies when a cell with potential $\mathrm{E}$ is connected to an external load $\mathrm{R}$ and can be expressed as

$$
E=E_{o}-\left[\left(\eta_{c t}\right)_{a}+\left(\eta_{c}\right)_{a}\right]-\left[\left(\eta_{c t}\right)_{c}+\left(\eta_{c}\right)_{c}\right]-i R_{i}=i R
$$

where

$\mathrm{E}_{0}=$ electromotive force or open-circuit potential of the cell (OCP)

$\left(\eta_{\mathrm{ct}}\right)_{a}\left(\eta_{\mathrm{ct}}\right)_{\mathrm{c}}=$ activation polarisation at the anode and cathode

$\left(\eta_{c}\right)_{a}\left(\eta_{c}\right)_{c}=$ concentration polarisation at the anode and cathode

$\mathrm{i}=$ load current

$\mathrm{R}=$ internal resistance of cell

As can be seen from the Eq. (1) that output potential is lower than the open-circuit potential $(\mathrm{OCP})$ due to the electrode and ohmic polarisation. The electrode and ohmic polarisations are small when the load-current is very low, and in that case the cell may operate close to OCP and deliver most of the total theoretical energy as electric energy, see Fig. 2.

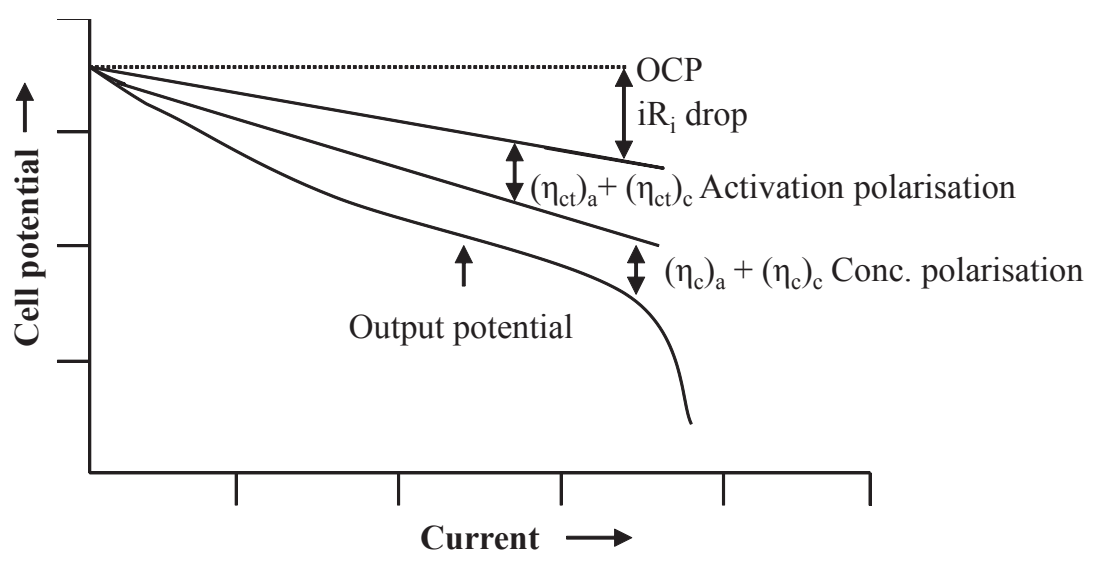

Figure 2. Cell potential as a function of current.

However, the available energy of a cell depends on the chemistry of the total system and principally the electrochemical reaction at both electrodes. There are some additional factors, which determine the kinetics of the charge-transfer reaction, the diffusion rate and degree of the energy loss. These factors include the electrode construction, cell engineering, electrolyte 
conductivity and nature of the separator, which will be discussed in detail in later sections. From a thermodynamic point of view, the reactions mainly occur at the two electrode interfaces, and during the discharge, the reaction at the cathode can be expressed by the following equation:

$$
a A+n e \rightarrow c C
$$

where a molecules of $\mathrm{A}$ are reduced to form c molecules of $\mathrm{C}$, and n number of electrons e are consumed. The reaction at the anode can be expressed by

$$
b B-n e \rightarrow d D
$$

where $\mathrm{b}$ molecules of $\mathrm{B}$ are oxidised and converted to $\mathrm{d}$ molecules of $\mathrm{D}$, and $\mathrm{n}$ electrons are released. The overall cell reaction is the sum of the above two half-cell reactions:

$$
a A+b B \rightarrow c C+d D
$$

The change in the standard free energy of this reaction is given by

$$
\Delta G^{o}=-n F E^{o}
$$

where $\Delta \mathrm{G}^{0}$ is the Gibbs free energy, $\mathrm{F}$ is the Faraday constant $(96,485$ Coulombs per mole) and $\mathrm{E}^{0}$ is the standard potential which depends on the type of the active material integrated into the cell. This can be further represented for the non standard state condition of both electrodes by the Nernst equation:

$$
E=E^{o}-\frac{R T}{n F} \ln \frac{a_{C}^{c} a_{D}^{d}}{a_{A}^{a} a_{B}^{b}}
$$

where $a_{i}$ is the activity coefficient of relevant species, $R$ is the gas constant $\left(8.31 \mathrm{JK}^{-1} \mathrm{~mol}^{-1}\right)$ and $\mathrm{T}$ is the absolute temperature $(\mathrm{K})$. The amount of electrical energy per mass or volume available for the external circuit is measured from the change in the standard free energy, the driving force of a battery. The total available energy in a cell is given by the following equation:

$$
\Delta G=-x n F E
$$

Where $\mathrm{x}$ is the molar quantity of the active materials involved during the discharge reaction. 
Theoretically, the capacity of a cell is calculated from the quantity of the active materials and is expressed as the total quantity of electricity from the electrochemical reactions within the cell represented in terms of Coulombs or Ampere-hours. One molar mass or gram equivalent weight of the active materials involved in the electrochemical reaction produces 96,485 Coulombs or 26.8 Ah capacity. For example, the theoretical capacity of Li-ion battery can be calculated as follows:

$$
\mathrm{Li}_{\mathrm{x}} \mathrm{C}_{6}+\mathrm{Li}_{1-\mathrm{x}} \mathrm{CoO}_{2}=\mathrm{LiCoO}_{2}+\mathrm{C}_{6}
$$

$\mathrm{x}=0.5$, for example and the capacity of the $\mathrm{LiCoO}_{2}$ is $0.140 \mathrm{Ah} / \mathrm{g}$

$$
\text { Watt hour }(\mathrm{Wh})=\text { Cell Potential }(\mathrm{V}) \times \text { Ampere hour }(\mathrm{Ah})
$$

As an example in the Li-ion battery with a standard potential of $4.1 \mathrm{~V}$ the theoretical Watt hour capacity per gram of the active materials (limited by the cathode capacity) is calculated as follows:

$$
\text { Gravimetric Specific Energy }\left(\mathrm{Whg}^{-1}\right)=4.1 \text { V X } 0.140 \mathrm{Ahg}^{-1}=0.574 \mathrm{Whg}^{-1} \text { or } 574 \mathrm{Whkg}^{-1}
$$

The practical energy density is decreased when the inactive materials, binders etc and the components of the electrolyte are included in the full cell calculations.

\subsection{Rechargeable lithium batteries for energy storage}

$\mathrm{Li}$ is attractive as the anode material for rechargeable batteries being the lightest metal (6.94 $\mathrm{g}$ $\mathrm{mol}^{-1}$ ), with a standard reduction potential of $-3.04 \mathrm{~V}$ (versus standard hydrogen electrode, SHE), resulting in the largest specific energy storage capability $\left(3861 \mathrm{mAhg}^{-1}\right)$. In the $1970 \mathrm{~s}, \mathrm{Li}$ metal was assembled in primary Li cells (non-rechargeable) for the first time, and because of their excellent capacity and discharge rate, they were used to power many electronic devices e.g. watches, calculators and implantable medical devices. [2] Around that time a number of inorganic compounds were also shown to have reversible-chemical reactivity with alkali metals opening up the possible use of intercalation compounds in lithium batteries. These materials were essential in the development of the high-energy Li-ion rechargeable batteries.

Early research used $\mathrm{TiS}_{2}$, as the cathode material and Li metal as the anode material.[3,4] However, issues with the metallic Li anodes, in particular dendritic Li growth on cycling (which caused short circuits) raised safety concerns for the use of Li metal and resulted in the investigation of alternative approaches with new electrolyte and negative electrode materials. The alloying of $\mathrm{Li}$ with metals or intercalation of $\mathrm{Li}^{+}$into metals or semiconductors such as $\mathrm{Si}$ emerged as the potential solution. This solved the dendrite problem but cycle life was significantly influenced by large volume changes of the alloy material during the Li-ion 
insertion/de-insertion process. Initially, LiAl alloy with a composition of 1:1 was used as anode material with large specific energy capacity $\left(780 \mathrm{mAhg}^{-1}\right)$ but a volume expansion of $200 \%$ resulted in electrode crumbling, loss of electrical contact and rapid capacity fading. [5]

In the late 1970's and early 1980's researchers proposed the substitution of metallic Li with a second insertion material as the anode which led to Li-ion or 'rocking chair' batteries (Fig. 3). $[6,7] \mathrm{Li}$ was thus incorporated in the ionic rather than the metallic form in the anode electrode which solved the dendrite problem leading to safer Li batteries. The ionic character of the anode material ( $\mathrm{Li}^{+}$intercalated material) increased the reversible anode potential and consequently a higher redox potential cathode material was needed to compensate for the anode. Layered or three-dimensional transition metal oxides, $\mathrm{Li}_{x} \mathrm{MO}_{2}(\mathrm{M}=\mathrm{Co}$, Ni or $\mathrm{Mn})$ which exhibit more ionic character than the transition metal disulfides became the cathode material of choice.[8,9] These commercially applicable cathode materials are still used to date in a large number of portable devices. $[10,11]$

The search for suitable Li ion anodes continued and after many years of extensive research carbonaceous materials with high reversibility were reported at a low $\mathrm{Li}^{+}$intercalation / deintercalation potential using liquid electrolyte at room temperature. [12,13] The discovery immediately led to the implementation of the rocking chair concept, and Sony Corporation, commercialised the $\mathrm{C} / \mathrm{LiCoO}_{2} \mathrm{Li}$-ion or rocking chair rechargeable battery with high energy density $\left(\approx 180 \mathrm{Whkg}^{-1}\right)$ and high discharge potential (3.7 V) in June 1991. [14] Li-ion rechargeable batteries are used in most of today's high-performance portable electronic devices.

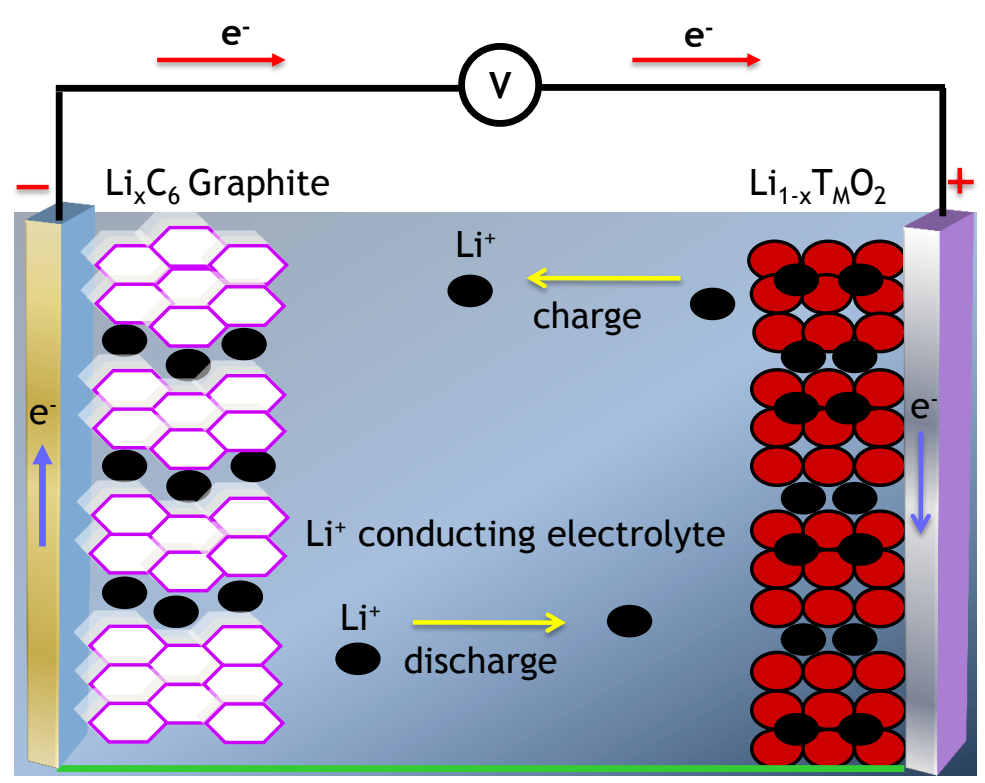

Figure 3. Representation of the lithium ion 'rocking-chair' rechargeable battery. 
A further development investigated the use of polymer based Li-on rechargeable batteries, socalled Li-ion solid polymer electrolyte (Li-SPE) batteries, by substitution of liquid electrolyte with dry polymer electrolyte. [15] However, the poor conductivity of the SPE at ambient temperature (typically requiring temperatures above $80^{\circ} \mathrm{C}$ ) has prevented their widespread application in portable electronic devices. However, a new class of electrolyte was introduced by mixing a small amount of typical organic solvents with the polymers and lithium salt resulting in a polymer gel electrolyte. The plasticiser organic liquid mixed with the polymer results in an ionic conductivity approaching that of solvent alone. [16,17] Polymer Li-ion (PLiON) batteries operate at ambient temperature and offer a thin-film design flexibility. [18]

\subsection{Electrode materials for Li ion batteries}

Lithium ion batteries are in widescale deployment. Fig. 4 shows the gradual improvement in energy density for $\mathrm{Li}$ ion systems that has occurred over the 20 years since their introduction commercially in 1991. The improvements are attributable to improved engineering of the materials, their structuring, processing and additives utilised. An equivalent scale is included on the right hand axis to indicate an equivalent energy density for a $10 \mu \mathrm{m}$ thin film version per $\mathrm{cm}^{2}$ footprint if it were possible to scale all of the materials of standard lithium cells. The value is very similar to the actual thin film versions in use today which have a lithium metal anode rather than carbon.

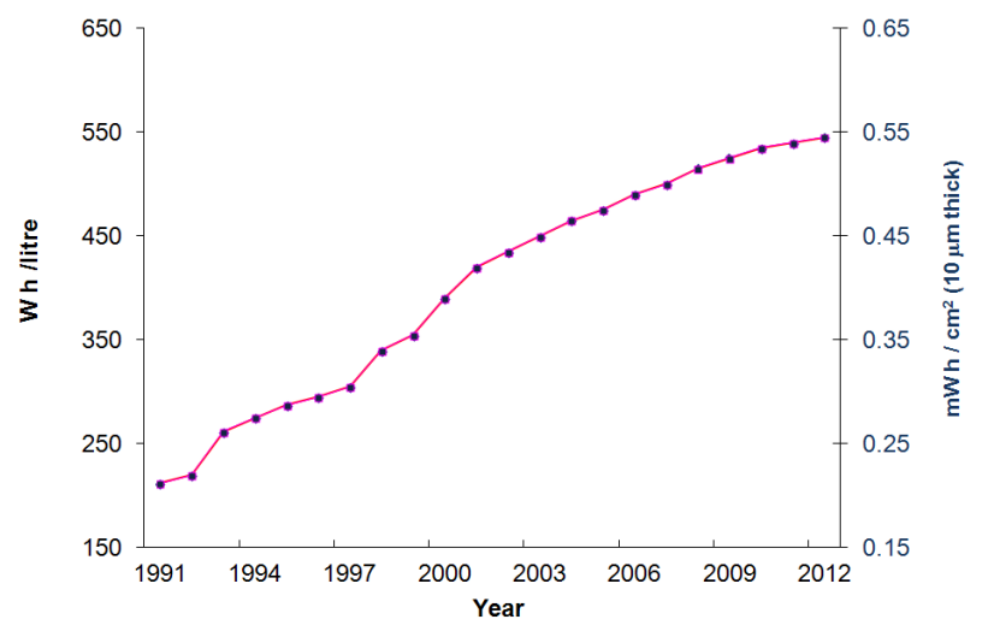

Figure 4. Li ion energy density improvements since 1991.

Carbon is used as the anode material in almost all commercially available Li-ion rechargeable batteries. Among the different types of carbon classified accordingly to their natural sources and structures, graphite (ABAB- layers) and hard carbon (polycondensation of oil pitch) are mostly used as anodes. The electrochemical intercalation has a Li capacity of $372 \mathrm{mAhg}^{-1}$ from the corresponding lithiated formula $\mathrm{LiC}_{6}$ at room temperature. [19-22] Due to the difference 
in structure hard carbon is able to incorporate $\mathrm{Li}^{+}$in the space between crystal particles as well as between the layers and as a result a higher capacity has been achieved in the hard carbon than the graphite within the same lithiated formula $\mathrm{LiC}_{6}$. [23] The drawbacks of using carbonaceous materials as anodes include low specific energy capacity and electrolyte reactivity at the irregular surface.

The low intercalation potential, only $0.3 \mathrm{~V}$ away from that of $\mathrm{Li}$, enables 3.5 to $4 \mathrm{~V}$ lithium batteries though the overall energy is approximately 10 times less than if a Li metal anode was employed. The proximity to the potential for lithium metal plating means that care must be taken in the operation of the battery to prevent overcharge and Li metal plating during which dendrites can form that penetrate the electrolyte separator and short the battery. Modifications are continuously being introduced and a few metals, e.g., Ag, Zn or Sn, coated graphite fibre have been reported as high charge/discharge capacity anode materials. [24] It is believed that the improvements afforded by the coating result from modified passivation films formed on the metal surface, which reduce the extent of reaction between the bare graphite and the electrolyte. At the same time research has been focused in the development of alternative anode material with both higher capacities and slightly higher intercalation potential compared to carbon $/ \mathrm{Li}^{+}$and $\mathrm{Li} / \mathrm{Li}^{+}$in order to avoid $\mathrm{Li}$ plating on the high rate charging.

\subsection{Anode materials}

Materials with advanced performance such as Li metal alloys have been considered as potential alternatives for carbonaceous anode materials. Although attractive in terms of higher gravimetric capacity, the cyclability has generally been very poor in deep discharge, due to large volume changes (up to 200\%) during $\mathrm{Li}^{+}$insertion and de-insertion, which causes mechanical disintegration and hence loss of electrical contact between the active material and the current collector. [25] To overcome this issue, attempts have been made to introduce an inactive phase (buffer matrix) into the Li alloy to suppress or compensate for the volume expansion in some extent, while still protecting the electrical pathway. [26] Such alloy systems are achieved by mixing two or more metals so that electrochemically active metal phases are embedded in electrochemically inactive phases to react with Li forming alloys. Recently, Sn based alloy compounds $\mathrm{Sn}-\mathrm{M}^{\prime}$, where $\mathrm{M}^{\prime}$ is an electrochemically inactive confining buffer have been studied extensively because of their higher specific capacity, such as Sn-Fe[27], Sn-Co [28], Sn-Zn-Cu [29] and Sn-Ni. [30] However, metal alloys still suffer from mechanical strains during Li insertion and de-insertion that leads to cracking and crumbling of the electrode. These alloys show much better cyclability over simple Li alloys at the cost of reversible capacity; consequently, further improvement is needed for the practical application in Li-ion batteries.

An approach to reduce the problems of volume changes by selecting intermetallic alloys, such as $\mathrm{Cu}_{6} \mathrm{Sn}_{5}$, InSb and $\mathrm{Cu}_{2} \mathrm{Sb}$ has also been considered because of strong inter-structural relationship between the parent compound and the respective lithiated products, $\mathrm{Li}_{2} \mathrm{CuSn}, \mathrm{Li}_{3} \mathrm{Sb}$. [31] Research has been focused on those alloys because they react with Li topotactically, which has a structure of cubic symmetry in the initial transitional phase that provides a stable host framework for both the incoming and extruded metal atoms. They expand isotropically and 
to a lower extent than most alternatives. In spite of this they still suffer from relatively poor cyclability due to electrical and mechanical disintegration and require further optimisation.

Another route to alleviate the poor cyclability of the metal alloys is to use nanocomposites of active and inactive materials. [32] Several reports have been published on nanocomposite anode materials, for example SnO based glasses [33], Sn-Fe-C [34], Sn-Mn-C [35], Si-C [36], and SnCo [37], which show improved cycling behaviour. It is argued that thenanosized metallic clusters suppress the associated strains, and thus enhance the reversibility of the alloying reaction. However, nanocomposites still exhibit large capacity losses in the first cycle and capacity fading in subsequent cycles. This is related to a combination of irreversible processes, such as aggregation of nanoparticles, irreversible trapping of $\mathrm{Li}^{+}$by host clusters and secondary reactions involving electrolyte decomposition and the formation of unstable passivation layers. Further strategies have been investigated to minimise such secondary electrolyte reactions by uniformly coating the alloy composite surface with a less reactive protecting layer. [38]

More recently hollow nanospheres of various materials including metals, oxides and semiconductors have been considered as potential anodes. [39-41] Preparation methods for nanospheres with hollow interiors typically involve the removal of sacrificial templates, including silica [42] and polymer latex spheres [43], or reducing metal nanoparticles. [44] The hollow $\mathrm{Li}$ active nanospheres serve as barriers to particle pulverisation and provide a large surface area to buffer the volume change in $\mathrm{Li}$ insertion/de-insertion, consequently improving the capacity retention. Hollow nanospheres of $\mathrm{Sb}$ with substantially superior capacity retention than its counterpart nanoparticles at higher rates have been reported. A schematic illustration of the $\mathrm{Sb}$ hollow nanospheres typical of nanosphere preparation routes investigated is shown in Fig. 5 below. [40] Among metal oxides, $\mathrm{SnO}_{2}$ has been widely studied with a theoretical specific Li storage capacity (ca. $790 \mathrm{mAhg}^{-1}$ ). The main obstacle in commercial application of the Sn based anode materials is the pulverisation that occurs on cycling. [45,46] Nanoparticles combined with elastic hollow carbon spheres such as Sn nanoparticles encapsulated within conductive carbon nanospheres have also been investigated. [47] The free space inside the shell left after materials loading (void volume) and the elasticity of thin carbon spheres accommodate the strains associated with $\mathrm{Li}^{+}$insertion/de-insertion, as the volume can expand or contract repeatedly.

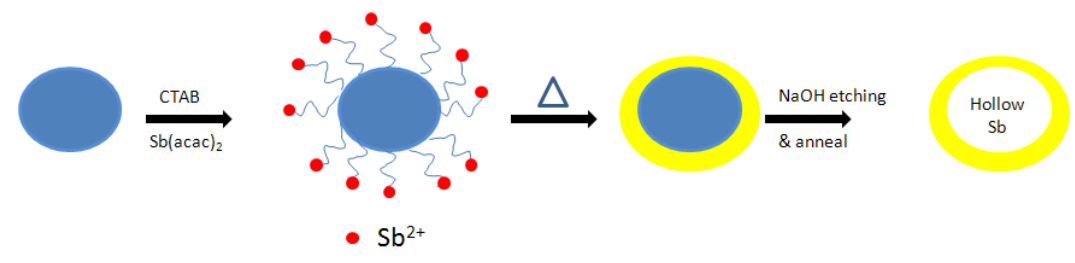

Figure 5. (a) Schematic illustration of the preparation of hollow Sb nanospheres from the CTAB (cetyltrimethylammoniumbromide) functionalised $\mathrm{SiO}_{2}$ templates.[40] 


\section{Cathode materials}

The materials for the cathode are typically selected according to the anode utilised. In rechargeable batteries with metallic $\mathrm{Li}$ as anode, the cathode does not need to be lithiated before cell assembly. On the other hand, in Li-ion batteries where the anode is made of Li active metals, alloys or carbon, the cathode should act as a source of $\mathrm{Li}^{+}$and thus involve the use of air stable $\mathrm{Li}$ intercalated compounds. $\mathrm{LiCoO}_{2}$ has been used as the cathode material since the first commercial Li-ion batteries were introduced, due to its structural stability (in limited cycling), ease of preparation and higher discharge potential than the counterpart dichalcogenides $\left(\mathrm{TiS}_{2}\right)$. [14] However, the specific capacity of the $\mathrm{LiCoO}_{2}$ is limited to only $140 \mathrm{mAhg}^{-1}$ at room temperature for $0.5 \mathrm{Li} / \mathrm{Co}$, although the desired theoretical value is $273 \mathrm{mAhg}^{-1}$. [48] The reduced specific capacity is associated with the restricted range of reversible cycling as almost delithiated $\mathrm{Li}_{\mathrm{x}} \mathrm{CoO}_{2}$, when $\mathrm{x}<0.3$, decomposes the electrolyte and causes electrode corrosion. The $\mathrm{LiCoO}_{2}$ delivers the best power density if discharged between $4.2 \mathrm{~V}$ to $3.0 \mathrm{~V}$ vs. $\mathrm{Li} / \mathrm{Li}^{+}$. $\mathrm{LiCoO}_{2}$ continues to be used in commercial batteries that power cell phones, laptops, etc., despite higher cost and both environmental and safety issues. But these issues limit their application where low cost and higher energy capacity is required, such as hybrid electric vehicles (HEV) or electric vehicles (EV).

Lithium nickel oxide, $\mathrm{LiNiO}_{2}$, which is isostructural with $\mathrm{LiCoO}_{2}$ has been considered because of slightly higher specific capacity, lower cost and much lower redox potential that diminishes electrolyte oxidation although safety concerns must also be addressed for this material most likely by the combination with additional metal oxides. $\mathrm{LiNi}_{1-\mathrm{x}} \mathrm{Co}_{\mathrm{x}} \mathrm{O}_{2}$ systems have been found to be more stable than the $\mathrm{Li}_{x} \mathrm{NiO}_{2}$, but further stabilisation of that layered structure is essential for safety and capacity issues. Several routes have been investigated and the addition of a redox-inactive di-, tri- or tetravalent cation ( $\mathrm{Al}, \mathrm{Ga}, \mathrm{Mg}$ or Ti) substitute for $\mathrm{Ni}$ or $\mathrm{Co}$ appears to be the most promising approach. [49-51] The substituted phases, such as $\mathrm{LiNi}_{1-x-y} \mathrm{Co}_{x} \mathrm{Al}_{y} \mathrm{O}_{2}$ are reported to be safer cathode materials for applications that require large energy capacity. [52] The substituted inactive-element prevents Li from deintercalating entirely and thus maintains the $\mathrm{O}_{2}$ partial pressure at a level that prevents possible structural collapse of the delithiated phase. SAFT incorporated these cathode materials for the first time in practical Li-ion batteries realising an energy density of 120-130 $\mathrm{Whkg}^{-1}$ even in deep discharge conditions. [53]

Layered $\mathrm{LiMnO}_{2}$ is another popular choice for the next generation Li-ion batteries not only as an abundant material source but also because it is environmentally benign. [54] The structure differs from that of $\mathrm{LiCoO}_{2}$ and $\mathrm{LiNiO}_{2}$ consisting of alternating zigzag layers formed from corner sharing between $\mathrm{LiO}_{2}$ and $\mathrm{MO}_{6}$ octahedra. $\mathrm{LiMnO}_{2}$ shows a specific charge capacity of $190 \mathrm{mAhg}^{-1}$ in the potential range of $2.0 \mathrm{~V}$ to $4.25 \mathrm{~V}$ with $99.9 \%$ capacity retention. Unfortunately, it follows the same fate of capacity fading upon delithiation owing to the presence of extra negative charge in the $\mathrm{MnO}_{2}$ layers. The structural instability of the layered $\mathrm{Li}_{x} \mathrm{MnO}_{2}$ phase has led to the investigation of the spinel $\mathrm{Li}_{x} \mathrm{Mn}_{2} \mathrm{O}_{4}$ structure with $3 \mathrm{D}$ channels which allow faster $\mathrm{Li}^{+}$diffusion upon cycling. [55]. Its implementation has been delayed mostly due to poor cyclability and low stability owing to dissolution of $\mathrm{Mn}^{+3}$ into the electrolyte at elevated 
temperature, which occurs at the particle surface in the presence of trace acids, especially HF. The dissolution of $\mathrm{Mn}^{+3}$ results in the formation of a defective spinel $\mathrm{LiMn}_{2} \mathrm{O}_{4}$ that reduces $\mathrm{Li}$ + insertion capacity. Partial substitution of the Mn by more electron rich elements, e.g., Co [56, 57] or $\mathrm{Ni}\left(\mathrm{LiMn}_{1-\mathrm{x}} \mathrm{Ni}_{\mathrm{x}} \mathrm{O}_{2}, 0<\mathrm{x} \leq 0.5\right)[58,59]$ has also been investigated. Although the initial specific capacity of these materials is as high as $200 \mathrm{mAhg}^{-1}$ they show poor cyclability upon overcharging. The role of the $\mathrm{Mn}$ is to stabilise the layered structure of $\mathrm{NiO}_{2}$, and the substituted $\mathrm{Ni}$ is redox and electrochemically active between the $\mathrm{Ni}^{+2}$ and $\mathrm{Ni}^{+4}$ states. The substituted Co within the structure controls the 3D channel in the spinel phase. More recently, the solid solutions of these lithiated transition metal oxides $\mathrm{LiMn}_{1-\mathrm{x}-\mathrm{y}} \mathrm{Ni}_{\mathrm{x}} \mathrm{Co}_{\mathrm{y}} \mathrm{O}_{2}$, have been shown to overcome structural instability although electrochemical performance of these materials largely depends on the synthesis techniques, conditions and stoichiometry. [60-66]

Phospho-olivine $\mathrm{LiFePO}_{4}$ phase has also been introduced commercially because it is plentiful, environmentally benign, low-cost, non toxic and has a competitive theoretical capacity of 170 mAhg-1 ${ }^{-1}$ higher than that obtained for layered $\mathrm{LiCoO}_{2}$ and $\mathrm{LiNiO}_{2}$. [67-69] The main disadvantage associated with $\mathrm{LiFePO}_{4}$ is poor electronic conductivity and consequently, significant efforts have been made to overcome this through chemical and physical processes. Carbon coatings on small $\mathrm{LiFePO}_{4}$ particles [70-72] or $\mathrm{LiFePO}_{4} / \mathrm{PPy}$ [73] (polypyrrole) composites have been utilised to enhance the capacity and rate capability of $\mathrm{LiFePO}_{4}$. Carbon coated porous $\mathrm{LiFePO}_{4}$ works well at low discharge rates but not at high discharge rates, due to the inadequate electronic conductivity of the material. Recently, the issue of poor electronic conductivity of porous $\mathrm{LiFePO}_{4} / \mathrm{C}$ composite has been addressed by introducing oxidic $\left(\mathrm{RuO}_{2}\right)$ nanoscale interconnects. [74] The $\mathrm{RuO}_{2}$ oxide coating repairs the gap between carbon conducting networks on porous $\mathrm{LiFePO}_{4}$ and thus improve the kinetics and rate capability of the LiFe$\mathrm{PO}_{4} / \mathrm{C}$ composite.

Vanadium pentoxide, $\mathrm{V}_{2} \mathrm{O}_{5}$, and its derivatives $(\mathrm{Cr}, \mathrm{Nb}$ and $\mathrm{Mo}$ ) were of the earliest studied cathode materials for their high specific capacity, low cost and ease of extraction from minerals. [75-77] The vanadium oxide family as well as dichalcogenides of transition metals $\mathrm{MX}_{2}(\mathrm{Ti}$, $\mathrm{Nb}, \mathrm{Ta}, \mathrm{Mo}$ and $\mathrm{W}$ ) have a $\mathrm{CdI}_{2}$-type structure, with disordered close-packed chalcogen layers between which the transition metals reside in either prismatic or octahedral coordination of six chalcogens. The theoretical capacity of $\mathrm{V}_{2} \mathrm{O}_{5}$ is the highest among other family members $\left(442 \mathrm{mAhg}^{-1}\right)$. However its rapid potential change with degree of $\mathrm{Li}^{+}$insertion that passes through different phases and low reaction rate makes it less manageable for practical applications. [78] At the same time a number of vanadium oxides, such as partially reduced $\mathrm{V}_{6} \mathrm{O}_{13}$ [79] and $\mathrm{LiV}_{3} \mathrm{O}_{8}$ [80] have also been studied with the conclusion that the electrochemical performance depends on the synthesis technique. [81]

To summarise, lithium ion cathode materials fall into two groups in general, the first with more compact lattice structure, such as $\mathrm{LiCoO}_{2}, \mathrm{LiNO}_{2}, \mathrm{LiMnO}_{4}$, substituted lithiated transition metal oxides $\left(\mathrm{LiCo}_{1-\mathrm{x}} \mathrm{Ni}_{\mathrm{x}} \mathrm{O}_{2}, \mathrm{LiNi}_{1-x} \mathrm{Co}_{\mathrm{x}} \mathrm{O}_{2}\right.$ or $\mathrm{LiMn}_{1-\mathrm{x}} \mathrm{M}_{\mathrm{x}} \mathrm{O}_{2}, \mathrm{M}=\mathrm{Ni}$ or $\mathrm{Co}$ ) or their solid solutions $\left(\mathrm{LiMn}_{1-\mathrm{x}-\mathrm{y}} \mathrm{Ni}_{\mathrm{x}} \mathrm{Co}_{\mathrm{y}} \mathrm{O}_{2}\right)$, and the second with more open structure like $\mathrm{V}_{2} \mathrm{O}_{5}, \mathrm{MnO}_{2}$ and olivine phase $\left(\mathrm{LiFePO}_{4}\right.$ or $\left.\mathrm{Li}_{3} \mathrm{~V}_{2}\left(\mathrm{PO}_{4}\right)_{3}\right)$. But most of the cathode materials exhibit low electronic conductivity ranging from $10^{-3} \mathrm{~S} \mathrm{~cm}^{-1}$ for $\mathrm{LiCoO}_{2}$ [82] down to $10^{-9} \mathrm{~S} \mathrm{~cm}^{-1}$ for $\mathrm{LiFePO}_{4}$. [83] which is fourteen orders of magnitude lower than $\mathrm{Cu}\left(5 \times 10^{5} \mathrm{~S} \mathrm{~cm}^{-1}\right)$ and thus surface or substrate 
modification is required to alleviate this problem. To improve the $\mathrm{Li}^{+}$insertion and extraction kinetics, reducing the size of such classical cathode materials is also necessary to achieve the short diffusion length and large contact area for higher current drain though it does also expose a greater area for unwanted electrolyte interaction. A nanosize coating that covers the whole surface of nanostructured active materials without contamination and aggregation is a great challenge. 1D nanowire and nanotube arrays or 3D macrostructures would be advantageous over nanoparticulate composites, and are discussed below. Li battery electrode materials and their electrochemical potential and capacity are summarised in Fig. 6.

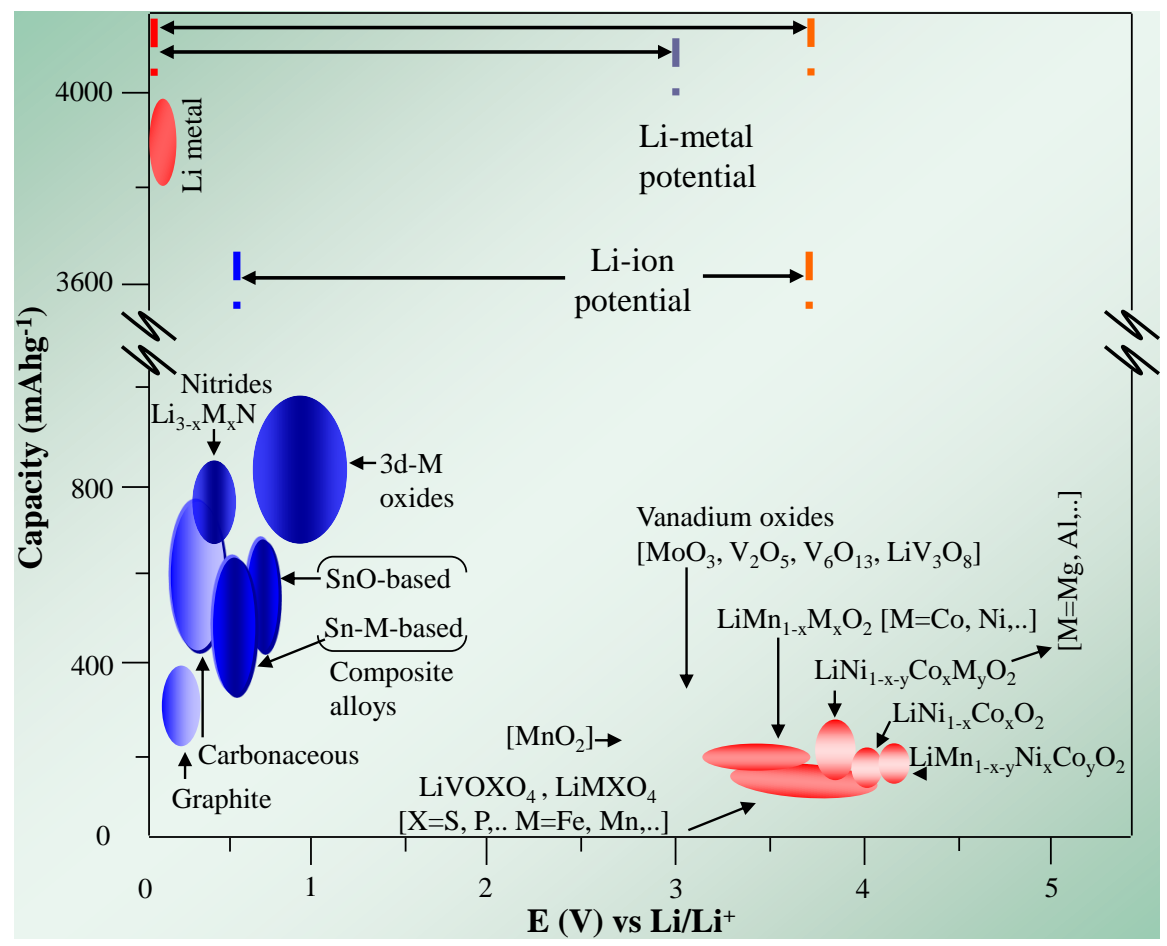

Figure 6. Schematic illustration of materials for negative and positive electrode in terms of capacity and potential currently used or projected for the next generation of rechargeable Li-ion or Li-metal batteries.

\section{Electrolytes}

In Li-ion battery systems organic solvents with a large stability window, good ionic conductivity, low melting and high boiling point and a low vapour pressure are required (see Table 1). Many studies have been carried out to choose suitable electrolytes for rechargeable lithium batteries based on thermal stability of the electrolytes [84-86] and electrochemical kinetics of 
the lithium ion in different mixed solvent electrolytes systems of various compositions. [87-88] The currently used cyclic carbonic acid esters like ethylene carbonate (EC) have high dielectric constant but high viscosity values due to the interaction between molecules which hinders mass transport of solutes. High dielectric constant solvents have high coulombic force between positive and negative sites in a molecule which results in a degree of ionic dissociation for the complex lithium salts. However, these cyclic carbonates show improved performance when mixed with a chain-like ester such as diethyl or dimethyl carbonate (DEC, DMC) whose viscosity and dielectric constant values are quite low. These solvents are commonly known as thinning solvents and it is for this reason that the solid phase of EC at room temperature is usually blended with these solvents.

\begin{tabular}{|c|c|c|c|c|c|c|}
\hline \multirow[t]{2}{*}{ Solvent } & \multirow{2}{*}{$\begin{array}{c}\begin{array}{c}\text { Dipole } \\
\text { Moment }\end{array} \\
(\mu / D)\end{array}$} & \multirow{2}{*}{$\begin{array}{c}\begin{array}{c}\text { Dielectric } \\
\text { Constant }\end{array} \\
\text { kor }(\varepsilon)\end{array}$} & \multicolumn{2}{|c|}{ Melting Point Boiling Point } & \multirow{2}{*}{$\begin{array}{l}\text { Density } \\
\left(\mathrm{g} / \mathrm{cm}^{3}\right)\end{array}$} & \multirow{2}{*}{$\begin{array}{c}\text { Molar Volume } \\
\left(\mathrm{dm}^{-3} / \mathrm{mol}\right)\end{array}$} \\
\hline & & & $\left({ }^{\circ} \mathrm{C}\right)$ & $\left({ }^{\circ} \mathrm{C}\right)$ & & \\
\hline Ethyl carbonate (EC) & 4.9 & 89.78 & 37 & 248 & 1.32 & 62 \\
\hline $\begin{array}{l}\text { Propylene carbonate } \\
\text { (PC) }\end{array}$ & 4.94 & 66.14 & -49 & 242 & 1.2 & 84 \\
\hline Diethyl carbonate (DEC) & 0.94 & 2.82 & -43 & 126 & 0.97 & 122 \\
\hline $\begin{array}{l}\text { Dimethyl carbonate } \\
\text { (DMC) }\end{array}$ & 0.88 & 3.12 & 3 & 90 & 1.06 & 84 \\
\hline
\end{tabular}

Table 1. Physical properties of organic solvents at $25^{\circ} \mathrm{C}$

EC

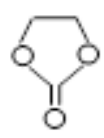

$\mathrm{PC}$

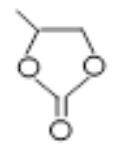

DMC

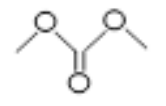

DEC

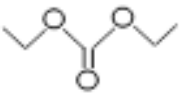

Figure 7. Structural formula of main organic solvents.

Although, $\mathrm{LiFP}_{6}$ electrolyte salt is stable in the above electrolytes it produces a strong Lewis acid, $\mathrm{PF}_{5}$, in the presence of trace amount of water by the following mechanism. [89] $\mathrm{PF}_{5}$ attacks the lone pair of electrons on the oxygen in water molecules and decomposes.

$$
\begin{gathered}
\mathrm{LiPF}_{6} \rightarrow \mathrm{LiF}+\mathrm{LiP}_{5} \downarrow \\
\mathrm{LiP}_{5}+\mathrm{H}_{2} \mathrm{O} \rightarrow \mathrm{PF}_{3} \mathrm{O}+2 \mathrm{HF}
\end{gathered}
$$

Thermal decomposition of $1 \mathrm{M} \mathrm{LiPF} / \mathrm{EC}: \mathrm{DEC}$ at $85^{\circ} \mathrm{C}$ is similar to the reaction between EC/DMC and $\mathrm{PF}_{5}$ gas. [90] Strong Lewis acids cleave the EC ring and produce transesterification products. Ethyl groups are electron donating, which is why PC is more reactive with 
$\mathrm{PF}_{5}$ and decomposes more easily than DEC. Since PC based mixed electrolyte is reported to decompose in contact with graphite anodes, an appropriate aprotic solvent mixture of EC/DEC has been recommended. [91-92]

It has been reported that the diffusion coefficient of EC based mixed electrolytes increases with increasing solute concentration though the solution viscosity increased with higher solute concentration. [15] The Li ion diffusion coefficient of the organic electrolyte systems cannot be directly extrapolated to their viscosity in terms of solute concentration, as other factors contribute such as ion solvation ability, ion conductivity, mass transport, solvent-solvent interaction, reduction and absorption of solvent on the electrode surface. The organic solvents PC and EC (Table 1) have nearly the same value of dipole moment and permittivity which is comparable with those values of water $(1.855 \mathrm{D}, 81 \varepsilon)$. The high solvation effect in organic electrolytes compensates for the increase of viscosity with increasing salt concentration.

The diffusion coefficient values for $\mathrm{Li}^{+}$increases in the order of $\mathrm{PC} / \mathrm{LiClO}_{4}<\mathrm{EC}$ : DEC (1:1)/ $\mathrm{LiPF}_{6}<\mathrm{EC}$ : DMC (1:1) $/ \mathrm{LiPF}_{6}$ with an increase from $0.1 \mathrm{M}$ to $1 \mathrm{M}$ in solute concentration.[93] The maximum diffusion coefficient values for lithium ion are $1.2 \times 10^{-5} \mathrm{~cm}^{2} / \mathrm{s}$ and $1.39 \times 10^{-5} \mathrm{~cm}^{2} / \mathrm{s}$ for $1 \mathrm{M} \mathrm{LiPF}_{6}$ in EC: DEC (1:1) and EC: DMC (1:1), respectively. In EC based mixed electrolytes lithium ion is coordinated by the EC rather than the acyclic carbonate (DEC, DMC) owing to high polarity and slightly higher donor number of EC (DN, 16.4 for EC, 15.1 for DEC and $\mathrm{DMC}$ ). Strongly solvated lithium ion complexes with high permittivity EC and reduces the ion association effect in low viscosity DEC or DMC. EC based mixed electrolytes of $1 \mathrm{M} \mathrm{LiPF}_{6} / \mathrm{EC} /$ $\mathrm{DEC}$ or $1 \mathrm{M} \mathrm{LiPF} / \mathrm{EC} / \mathrm{DMC}$ have become the liquid electrolytes of choice for use in lithium rechargeable batteries.

To minimise safety issues in Li-ion rechargeable batteries all solid electrolyte are very attractive. Armand et al. first investigated the ionic conductivity of $\mathrm{Li}^{+}$in solid state polyethylene oxide (PEO) polymer and applied it to Li-ion rechargeable batteries. [15]. These electrolytes are intrinsic solid polymer electrolytes (SPE) and the crystallinity favoured at lower temperature decreases the ionic conductivity. To achieve higher conductivity electrolytes at room temperature polymers were mixed with small amounts of the typical aprotic solvents known as plasticiser, such as, EC, PC, DEC and DMC. [93]. Polymer-gel electrolytes consist of polymer networks swollen with liquid(s) and possess both the cohesive properties of solids and ionic transport properties like liquids. Polymer gel electrolytes are alternatively called "polymer hybrid" or "gelionics".

Polymer gels containing alkali metal salt trapped within the matrix of the polymer host were first demonstrated by Feuillade et al. in 1975, with an ionic conductivity close to that of the liquid electrolytes. [94] Afterwards, polymer gel electrolytes with a variety of polymer hosts, such as polyethylene oxide (PEO) [95] polyvinylidene fluoride (PVdF) [96,97] polyacrylonitrile (PAN) [98,99] polymethyl methaacrylate (PMMA) [100,101], polyvinylidene fluoride-hexafluoropropylene (PVdF-co-HFP) \{102,103] have been reported with the ionic conductivity values in the range of $10^{-4}$ to $10^{-3} \mathrm{~S} \mathrm{~cm}^{-1}$ at ambient temperature. The plasticisers increase the amorphous character of the host polymers with a single glass transition temperature $(\mathrm{Tg})$ below $-40^{\circ} \mathrm{C}$. Thus, the ionic conductivity of gel electrolytes increases through enhanced diffusive transport in the liquid phase. PAN and PVdF-based polymer gels are the most widely 
studied electrolyte systems. PAN-based gel electrolytes with dispersed lithium salts, for instance, $\mathrm{LiClO}_{4}, \mathrm{LiAsF}_{6}$ and LiTFSI, have been shown to have very high ionic conductivity and $\mathrm{Li}^{+}$transfer number. [104] However, these electrolyte systems could be applied in batteries only with intercalation electrodes, because of the high reactivity with Li metal.

PVdF has enhanced capability to dissociate Li salts due to the strong electron withdrawing functional group (-C-F) in the host structure as well as a high dielectric constant $(\varepsilon=8.4)$. Castpolymer-gel electrolyte films based on PVdF solid polymers mixed with plasticisers EC/PC and $\mathrm{Li}$ salts, for example, $\mathrm{LiCF}_{3} \mathrm{SO}_{3}, \mathrm{LiPF}_{6}$ or LiTFSI have been prepared by Jiang et al. [105] The mechanical stability of these PVdF-based gel electrolytes varied with the amount of the solid polymer and the concentration of the dispersed Li salts determined the total ionic conductivity. However, PVdF-based gel electrolytes are also unstable towards Li metal and Li salts due to the fluorinated polymer host, which produces poor interfacial characteristics. The co-polymerisation of PVdF with hexafluoropropylene (HFP) has been reported to enhance the electrolyte properties significantly, giving higher solubility rates in organic solvents and lower crystallinity with a reduced glass transition temperature (Tg) than pure PVdF in the gel. \{106]. Although, the polymer-gel electrolytes have high ambient ionic conductivity the mechanical strength is decreased and a higher interfacial impedance is observed due to the passivation layer at the $\mathrm{Li} / \mathrm{Li}^{+}$interface. [107-110]

Recently, the problems associated with the polymer-gel electrolytes have been minimised by introducing nanocomposite gel polymer electrolytes instead of conventional/gel/plasticised polymer electrolytes, but at the cost of a slight decrease in the conductivity value. The dispersion of nano-ceramic filler particles $(\sim 10 \% \mathrm{w} / \mathrm{w})$, such as $\mathrm{Al}_{2} \mathrm{O}_{3}, \mathrm{SiO}_{2}$, and $\mathrm{TiO}_{2}$, into polymer gel electrolytes increases the mechanical stability, where nanoparticles act as physical and chemical barriers to the solvents evaporation from the system. [111] The technologies based on either solid or hybrid polymer electrolytes offer great advantages to meet the shape and design flexibility requirements for miniaturisation of electronics and other portable devices. Additionally, solid Li-polymer technology enables excellent packaging efficiency without the possibility of solvent leakage.

\section{Energy storage materials and architectures at the nanoscale}

Nanotemplated materials have significant potential for applications in energy conversion and storage devices due to their unique physical properties. Nanostructured materials provide additional electrode surface area with short path lengths for electronic and ionic transport and thus the possibility of higher reaction rates. [112-114] Control of the active materials at the nanoscale is required for battery materials where solid-state ionic diffusion is a limiting factor in the electrode reactions. Template mediated fabrication is a potential method for ordered high density array fabrication of nanowire/nanotube on metallic current collector substrates. Early reports of nanotemplated materials focused on the use of polymer templates. [115-117] Subsequently, higher pore density anodic aluminium oxide (AAO) substrates $\left(10^{9}\right.$ to $10^{11} / \mathrm{cm}^{2}$ by comparison with $10^{8} / \mathrm{cm}^{2}$ for track etched polycarbonate) have been developed. [118] It is 
also possible to form pores with smaller diameter (to low 10's of nm level) vertically aligned for more ordered channels and active materials. AAO processing on Si has been investigated [119-121] and is under development as a means to optimise the materials nanotemplating and integration of passive devices with silicon technology. [122,123] Other fabrication methods include vapour-liquid-solid (VLS) growth. [124] VLS growth combined with chemical vapour deposition (VLS-CVD) [125] and template mediated micelle deposition. [126] Optimising active materials and architectures not only requires assessment of the electrochemical properties for the given application but also the electrical and mechanical characteristics during reaction.

1D nanowires or nanotubes have anisotropic morphologies and self-supported arrays grown directly on a current collector represent an attractive architecture for Li-ion batteries. Such arrays can ensure that each nanowire or nanotube participates in the electrochemical reaction with 1D electron transport pathways. Arrays of nanowires and nanotubes eliminate binders or additives that decrease power density by incorporating extra inactive materials in the total weight. Moreover, they can accomodate strain during charge and discharge. $[127,128]$ Nanotubes function as electrolyte-filled channels for faster ionic and mass transport to the remote electrode surface. A variety of synthesis methods for the preparation of 1D nanowire or nanotubes for use as Li battery electrode materials have been investigated including sol-gel processing combined with template synthesis or hydrothermal treatment. The following is a brief review of recent progress in advanced anode and cathode materials for use in Li-ion batteries.

\subsection{Anode materials at the nanoscale}

A number of metals and semiconductors, for instance, $\mathrm{Al}, \mathrm{Sn}, \mathrm{Si}$, accommodate a large number of Li atoms per formula unit in electrochemical reactions, and provide higher specific capacity than that offered by the conventional graphite. Unfortunately, large volume changes and phase transitions in the host metal accompany the reactions. Attempts to limit the mechanical strains generated during Li ion insertion and removal were discussed in the earlier section including the use of active/inactive nanocomposites, hollow nanospheres and nanoparticles encapsulated with elastic shells. Although, nanocomposites or nanospheres considerably suppress the associated strains, and thus improve the reversible capacity, unsolved issues include low energy density of the electrode due to the poor packing density and the large proportion of inactive binders, additives, etc., in the electrodes. [129]

1D nanowires or nanotubes of metals, semiconductors or oxides provide a route to enhanced battery materials as they suppress strains, minimise pulverisation and provide good electronic contact and conduction pathways when grown directly on the current collector. $\mathrm{Cu}_{6} \mathrm{Sn}_{5}$ nanowires [130] with a measured height of $5 \mu \mathrm{m}$ and diameter of $250 \mathrm{~nm}$ or an aspect ratio of 20 have been studied by cyclic voltammetry, figures 8 and 9. The first charge and discharge capacity of the nanowires was $325 \mathrm{mAh} / \mathrm{g}$. The charge-discharge capacity is stabilised at 175$200 \mathrm{mAh} / \mathrm{g}$ from the third cycle with no significant deterioration. The obtained results imply that a topotactic reaction mechanism for $\mathrm{Li}^{+}$insertion/extraction is established with suppressed 
irreversible capacity loss due to the non-transferable lithiated transition phase and oxide impurities. [131, 132]

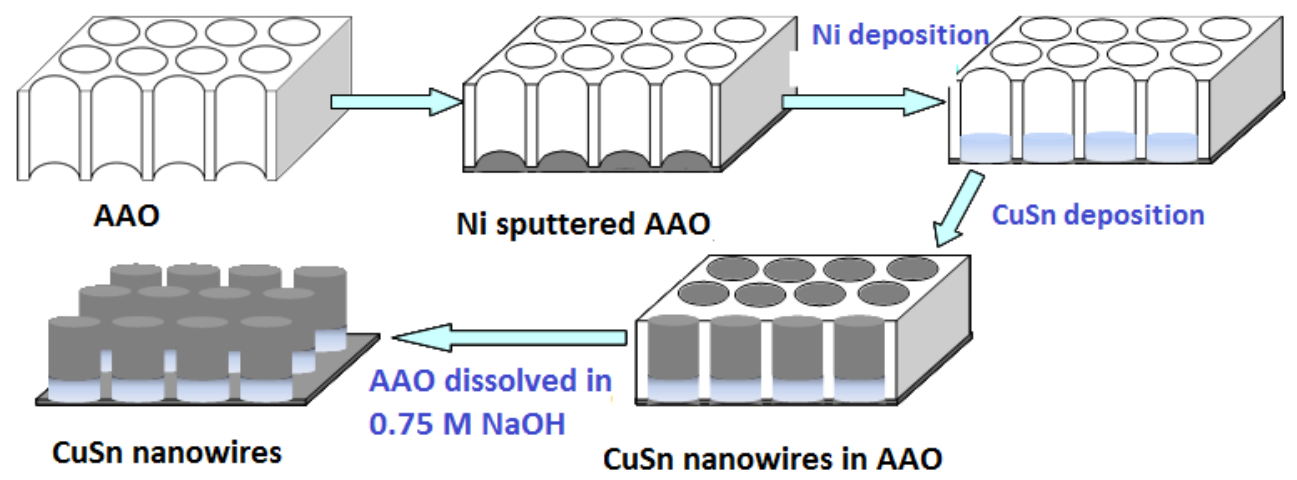

Figure 8. Schematic of templated CUSn nanowire fabrication process using Ni backed AAO.

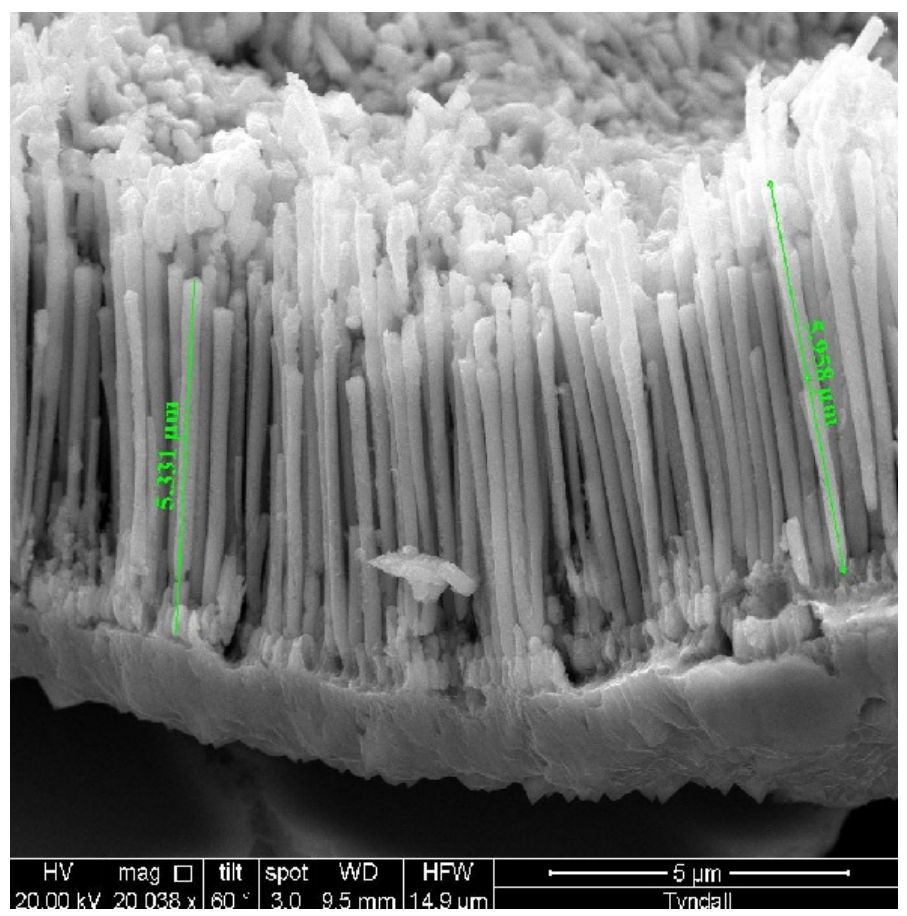

Figure 9. CuSn nanowires grown on Ni supports in an AAO template. 
Alternative high capacity anode materials that have received attention as potential replacements for carbon and that may be processed on Si for micro energy storage include, Sn (990 $\mathrm{mAh} / \mathrm{g}) \mathrm{Ge}(1,600 \mathrm{mAh} / \mathrm{g})$ and $\mathrm{Si}(4,200 \mathrm{mAh} / \mathrm{g})$. In each case the materials can intercalate up to 4.4 moles of Li per mole and as a result suffer significant expansion and contraction on lithium cycling. Whitehead et al [133] reported that mesoporous Sn may be deposited from lyotropic liquid crystal electrolytes and that the mesoporous Sn exhibited enhanced capacity and a slower loss of capacity than non templated Sn. The capacity did, however, drop below $400 \mathrm{mAh} / \mathrm{g}$ within 10 cycles. Vertical arrays of one-dimensional Sn nanowires on silicon dioxide $\left(\mathrm{SiO}_{2}\right)$ /silicon $(\mathrm{Si})$ substrates have been developed as anode materials for lithium rechargeable microbatteries. For these $1 \mathrm{D}$ nanowires a discharge capacity of $400 \mathrm{~mA} \mathrm{~h} / \mathrm{g}$ could be maintained after 15 cycles at the high discharge/charge rate of $4200 \mathrm{~mA} / \mathrm{g}$. [121] Ge semiconductor has a theoretical capacity of $1600 \mathrm{mAhg}^{-1}$, significantly higher than $\mathrm{C}$ but less than half that offered by Si. It has the advantage of a 400 times higher diffusivity for Li than Si. [134] Ge nanowires were fabricated by a template-free VLS method combined with CVD on the same stainless steel substrate using Au as catalyst and found to have initial discharge capacity of $1141 \mathrm{mAhg}^{-1}$ at the $0.05 \mathrm{C}$ rate. [125] The capacity dropped to approximately 600 $\mathrm{mAh} / \mathrm{g}$ at higher rates but with these values retained to at least 20 cycles indicating that nanostructured anodes can retain capacity despite large volume changes on cycling.

$1 \mathrm{D} \mathrm{SnO}_{2}$ materials are one of the most extensively researched nanostructured anode materials for high-energy density Li-ion batteries. [135-137] Recently, highly ordered amorphous-CNT coated single crystal $\mathrm{SnO}_{2}$ nanowire arrays have been fabricated by drying and annealing the $\mathrm{SnO}_{2}$ sol-gel filled AAO template using citric acid as chelating agent. [127] These amorphous-CNT coated single crystal $\mathrm{SnO}_{2}$ nanowires have shown reversible capacity of $418 \mathrm{mAhg}^{-1}$ in the first cycle and capacity retention of $353 \mathrm{mAhg}^{-1}$ after 30 cycles. Nanotubes of the polycrystalline $\mathrm{SnO}_{2}$ have been synthesised through an infiltration technique using $\mathrm{SnO}_{2}$ nanoparticles as starting building units and $\mathrm{AAO}$ as template. [138] The tubular templated $\mathrm{SnO}_{2}$ nanoparticles have demonstrated a significant improvement of the specific capacity and the cyclability over their non-templated nanoparticle counterparts, and a reversible capacity of $525 \mathrm{mAhg}^{-1}$ was retained after 80 cycles. A similar approach of using $\mathrm{SnO}_{2}$ nanotubes as high performance anode materials has been reported where nanotubes were synthesised first, and then a uniform CNT over-layer was grown on the external surface of the $\mathrm{SnO}_{2}$ nanotubes through an AAO template assisted spaceconfined catalytic decomposition process. [139] The $\mathrm{SnO}_{2}$-core-C-shell nanotubes obtained have been shown to deliver a higher reversible capacity of about $600 \mathrm{mAhg}^{-1}$, and excellent cyclability with capacity retention of $92.5 \%$ after 200 cycles. The enhanced electrochemical performances were assigned to the unique features of $\mathrm{SnO}_{2}$ nanotubes, including flexible thin walls that accommodate strains uniformly caused by electrode volume change, and open ends allowing more efficient $\mathrm{Li}^{+}$insertion and transportation.

The electrode reactions using classical intercalation materials involve the insertion (or deinsertion) of $\mathrm{Li}^{+}$into (or from) an open host structure with a concomitant addition or removal of electrons. Taberna et al., extended the idea of the so called "conversion reactions" to $1 \mathrm{D}$ $\mathrm{Fe}_{3} \mathrm{O}_{4}$ nanowire structures, the reaction mechanism is different from the classical $\mathrm{Li}^{+}$insertion/ 
de-insertion. [140] High capacity and rate capability, for example, 80\% capacity retention at $8 \mathrm{C}$ rates, have been reported using these nanowire arrays. The specific capacity of $\mathrm{Fe}_{3} \mathrm{O}_{4}$ is considered about $928 \mathrm{mAhg}^{-1}$ by assuming the reduction of the host metal ions $\mathrm{F}^{+3}$ or $\mathrm{Fe}^{+2}$ to $\mathrm{Fe}^{0}$ during $\mathrm{Li}^{+}$interaction. Mesoporous $\mathrm{CO}_{3} \mathrm{O}_{4}$ nanowires of the same "conversion reactions" family have been synthesised by an ammonia-evaporation-induced method on various substrates such as $\mathrm{Si}$ wafer, glass slide, $\mathrm{Cu}$ or Ti foil, and polystyrene. [141] This is a mild template-free method, which allows the growth of large area nanowire arrays and many choices for substrate. The mesoporous $\mathrm{Co}_{3} \mathrm{O}_{4}$ nanowires have shown high specific capacity, good cyclability and high rate capability. They are reported to maintain a stable capacity of $700 \mathrm{mAhg}^{-1}$ at $1 \mathrm{C}$ rates after 20 cycles but at higher rates the capacity decreased to $85 \%, 69 \%$ and $50 \%$ when discharged at $8 \mathrm{C}, 20 \mathrm{C}$ and 50C, respectively. The main issue with such conversion reaction anodes is the large hysteresis between charge and discharge and the resulting relatively high cut-off potential, which can be as much as $3 \mathrm{~V} v \mathrm{vs}$. $\mathrm{Li}^{\prime} / \mathrm{Li}^{+}$, required to achieve full capacity. In this laboratory we fabricated $\mathrm{Cu}$ nanotubes [142] and converted the outer surface to $\mathrm{Cu}_{2} \mathrm{O}$ though the use of an oxygen plasma ash for use in lithium batteries, figure 10. The oxide shell thickness is readily controlled exhibiting a linear relationship with time. [143] Over-oxidising the $\mathrm{Cu}$ nanotubes led to a poor cyclability (capacity loss within 10 cycles) for the anodes based on the loss of mechanical support for the active materials and the high conductivity $\mathrm{Cu}$ core. On the other hand when a core-core was maintained the electrodes cycled without loss of capacity for more than 90 cycles. This core-shell processing is therefore worth exploring to develop alternative anodes that do not suffer from the large hysteresis currently experienced by conversion anodes.
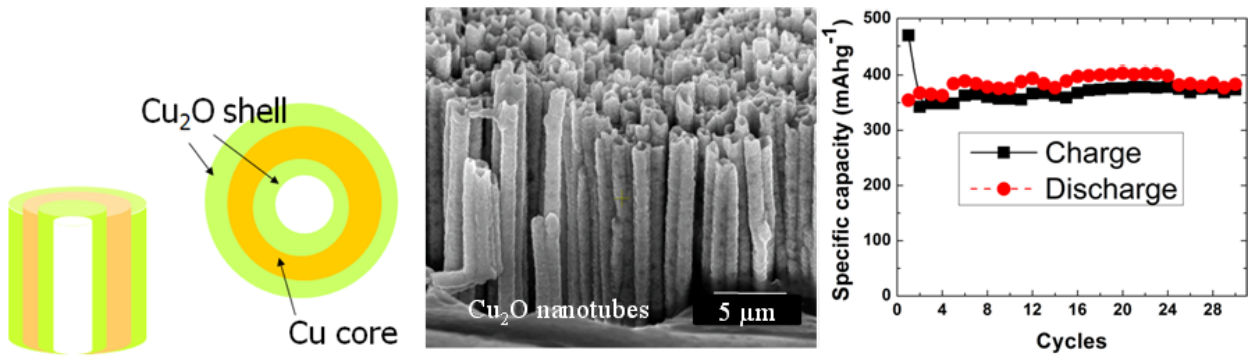

Figure 10. $\mathrm{Cu}_{2} \mathrm{O}$ nanotubes for core/shell battery anode materials.

Si nanowires, are one of most attractive anode materials for $\mathrm{Li}$-ion batteries and have also been synthesised by the template free VLS method on stainless steel substrate using Au as catalyst, and they are found to demonstrate higher capacity $\left(4,277 \mathrm{mAh} \mathrm{g}^{-1}\right.$ at very low $\mathrm{C} / 20$ rates) than other structured forms of Si. [144] In a subsequent paper [145] they showed that control the potential limit for Li intercalation had a significant impact on cycle life through suppression of the crystallization of a-Si of the Si nanowires. The capacity retention was observed to decrease steadily after 10 to 20 cycles even with the control of the lower limit for cycling. To overcome the issue of capacity fade that group succeeded in fabricating core-shell, crystalline- 
amorphous Si anodes [146] which achieved significantly improved cycle retention at the cost of lower energy density of apprximately $1000 \mathrm{mAh} / \mathrm{g}$ for Si. Recently, mesoporous Si-C coreshell nanowires have been prepared by Cho et al. using highly ordered mesoporous SBA-15 silica templates consisting of hexagonal arrays of 2D parallel cylindrical pores. [147]. The mesoporous Si-C nanowires have demonstrated initial charge specific capacity $3163 \mathrm{mAhg}^{-1}$ and a capacity retention $87 \%$ after 80 cycles at low $0.2 \mathrm{C}$ rates. Such core-shell anode materials are of significant interest for future battery anodes and optimised materials and structures are required that will facilitate the high energy density coupled with high rate capability and with a footprint dimension no larger than the electronics they power.

\subsection{Cathode materials at the nanoscale}

A number of reports of 1D nanowire and nanotube transition metal oxides as $\mathrm{Li}$ ion cathodes have been published. Martin et al. investigated polycrystalline $\mathrm{V}_{2} \mathrm{O}_{5}$ nanowires $(70 \mathrm{~nm})$ which delivered significantly higher specific capacity than micrometer-sized diameter electrodes at low temperature. [148, 149] 1D battery electrodes meet the challenge for working at low temperature by confining the dimensions of the electrodes for enhanced $\mathrm{Li}$ ion diffusion. Cao et al. reported a template based electrodeposition method for single crystalline $\mathrm{V}_{2} \mathrm{O}_{5}$ nanowires by applying an electric field around the solution or sol. $[150,151]$ Such nanowire arrays have been reported to possess higher capacity and higher rate capability than the polycrystalline thin film counterparts. Mixed valency vanadium oxide nanotubes $\left(\mathrm{VO}_{\mathrm{x}}-\mathrm{NTs}\right)$ have been prepared using a sol-gel reaction, followed by a hydrothermal step, from vanadium alkoxide precursor and primary monoamines that function as molecular structural directing template. [152] Wang et al. prepared nanotube arrays of amorphous $\mathrm{V}_{2} \mathrm{O}_{5}$ using the template based electrodeposition method at lower voltages and shorter deposition times than the conditions for preparing nanowires. [153] The initial Li capacity of the $\mathrm{V}_{2} \mathrm{O}_{5}$ nanotubes is reported to have specific capacity of $300 \mathrm{mAhg}^{-1}$, about two times higher than that of the $\mathrm{V}_{2} \mathrm{O}_{5}$ film (140 $\mathrm{mAhg}^{-1}$ ), resulting from the increased surface area and smaller $\mathrm{Li}^{+}$diffusion paths. The reported capacity for the nanotubes after 10 cycles, of $160 \mathrm{mAhg}^{-1}$, was 30\% higher than thin film electrodes.

Despite the excellent electrochemical performance of the traditional layered type $\mathrm{V}_{2} \mathrm{O}_{5}$ cathode material that accommodates intercalated $\mathrm{Li}^{+}$between the interlayers, there are also some other oxides showing high $\mathrm{Li}$ storage capacity by electrochemically reacting with $\mathrm{Li}^{+}$ions. West et al. prepared freestanding nanowire arrays of amorphous $\mathrm{MnO}_{2}$ by electrodeposition into anodised alumina membranes and these are capable of multiple charge-discharges with specific capacity of approximately $300 \mathrm{mAhg}^{-1}$ in a half cell reaction. [154] Despite the relatively large surface area the electrodes could only be discharged at $100 \mu \mathrm{A} / \mathrm{cm}^{2}$ before significant polarisation losses were observed.

A comparison of micron scale and nanoscale $\mathrm{MnO}_{2}$ (figure 11 (a) material as a lithium ion cathode is shown in figure 11(b). Data is included for micron scale commercial $\mathrm{MnO}_{2}$ powder. Also shown is the data for the $18 \mu \mathrm{m}$ in length $250 \mathrm{~nm}$ diameter $\mathrm{MnO}_{2}$ nanowires on $\mathrm{Cu}$ supports. In the first cycle for the nanowires an improvement is observed for the peak position and rate capability of the lithium insertion and extraction with respect to the micron scale 
material. The influence of the copper support is seen, however, at the more positive potentials and the electrode did not function as expected after the first sweep to the high positive potentials. Support materials more stable at the high positive potential are required such as nickel and/or alloy nanotubes [155] or aluminium which is typically used in commercial Li ion batteries operating in the potential range of the $\mathrm{MnO}_{2}$.
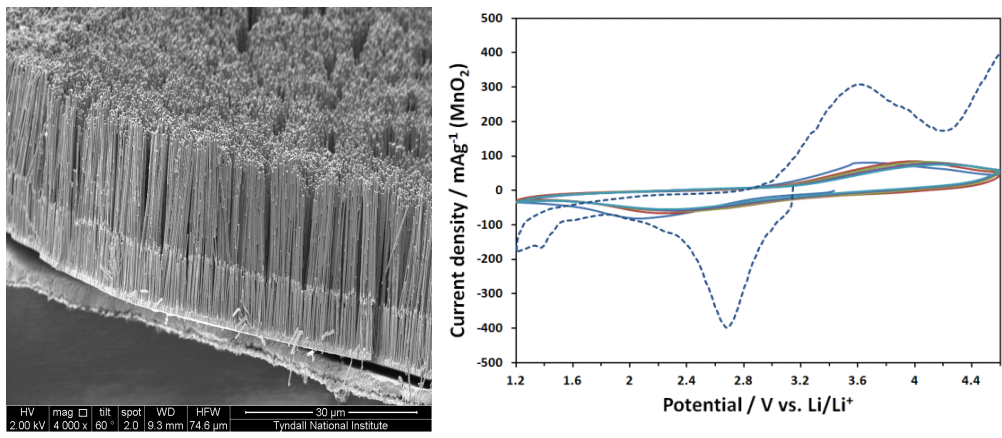

Figure 11. Free standing ramsdellite $\mathrm{MnO}_{2}$ electrodeposited on $\mathrm{Cu}$ nanotubes in an $\mathrm{AAO}$ template following removal of the template.

A topochemical method has been described in the synthesis of various nanostructured spinels of $\mathrm{LiMn}_{2} \mathrm{O}_{4}$ with high crystallinity, such as nanowires, nanohorn microspheres and hollow nanospheres, using nanostructured $\alpha$ and $\gamma \mathrm{MnO}_{2}$ as precursors. [156]. These nanostructured products are reported mostly as single phase cubic spinel $\mathrm{LiMn}_{2} \mathrm{O}_{4}$ and show higher capacity retention at rates up to $5 \mathrm{C}$. These studies are aimed at improving the structural stability by decreasing the rate of Mn dissolution at elevated temperature. Recently, two reports have been published dealing with improvements in both the rate capabilities and Mn dissolution from metal oxide coatings on spinel $\mathrm{LiMn}_{2} \mathrm{O}_{4}$ nanowires. [157,158] The coated nanowires demonstrate a comparable rate capability to uncoated counterparts but enhanced structural stability in storage at $80^{\circ} \mathrm{C}$ for 24 hours. Nanotubes of layered $\mathrm{LiCoO}_{2}, \mathrm{LiNi}_{0.8} \mathrm{Co}_{0.2} \mathrm{O}_{2}$ and spinel $\mathrm{LiMn}_{2} \mathrm{O}_{4}$, have been fabricated by AAO template assisted thermal decomposition methods. [159] 1D nanotubes of the open ended lithiated transition metal oxides with uniform shape and sizes and demonstrated gradually decreasing discharge capacities of 170, 150 and 100 $\mathrm{mAh} / \mathrm{g}$, respectively, at 100 cycles when cycled at $10 \mathrm{~mA} / \mathrm{g}$.

\subsection{Nanomaterials for advanced electrode and battery architectures}

The majority of commercial batteries are essentially composed of 2D planar films of electrodes and electrolyte. Such an arrangement has been sufficient for energy storage and power delivery to date. However, It is not feasible to have very thick electrodes if the energy stored must be accessed at a high rate which places a limit on the dimensions of the active materials as a result the energy and power capability. For non-aqueous liquid or polymer gel lithium ion batteries this limits the electrode thickness values to approximately $100 \mu \mathrm{m}$. Much thinner battery 
materials (micron scale) are utilised in purely solid state versions such as sputter deposited microbatteries (figure 12). In both cases a limiting factor is the lithium ion diffusion characteristic in the solid state active material.

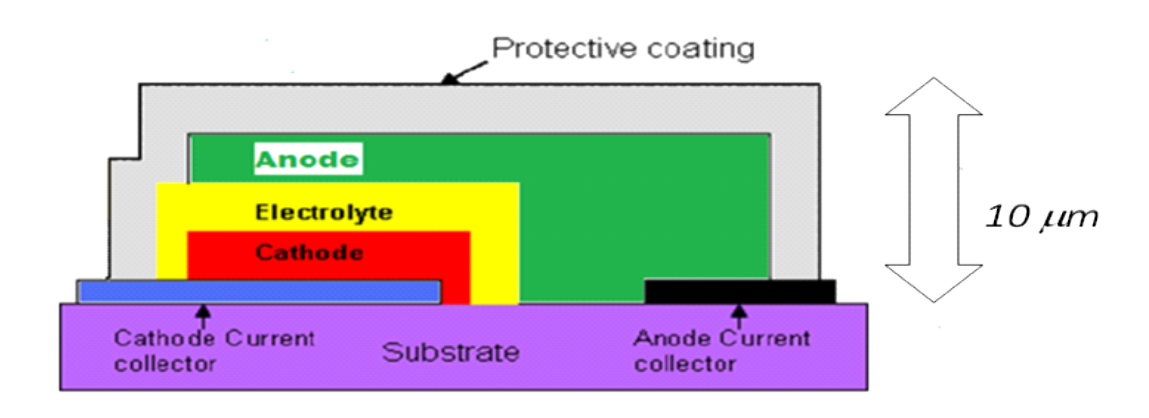

Figure 12. Typical lithium thin film microbattery cross sectional schematic.

Since the mid 1990's [160] work has been progressing on the development of solid state lithium microbatteries appropriate to integration on Si for enhanced microelectronic systems. The development of the LiPON electrolyte has been a significant milestone in microbattery fabrication. [161] Using vacuum deposition techniques planar films of the active components can be deposited and encapsulated leading to thin film energy storage devices that operate with high reproducibility for tens of thousands of cycles. The main issue with such micro energy storage sources is the limited energy that can be stored in micro scale thin films where for example a footprint of $6.5 \mathrm{~cm}^{2}$ is required to store approximately $4 \mathrm{mWhr}$. To decrease the footprint the active materials must be structured in high aspect ratio. The most common architectures proposed have been discussed in a detailed review. [112] In general it can be stated that to deliver $4 \mathrm{mWh}$ the same energy storage capability in a significantly decreased footprint of $1 \mathrm{~mm}^{2}$ design which is more appropriate to Si technology the active materials energy capacity must be improved by 3 to 4 times and the materials structured to increase the surface area by 30 times. This is a significant challenge and requires an ability to process active materials at the nanoscale.

2D thin film batteries, figure 13 (a), are limited by the slow transport of $\mathrm{Li}^{+}$ions and inaccessibility to materials at the back of the plates. On the other hand, 3D or 1D architectured battery materials, figure 13 (b) offer the possibility for short $\mathrm{Li}^{+}$transport paths to maximise power and energy density if in high aspect ratio. The general strategy for non-planar cell design is to configure electrodes in periodic or aperiodic arrays to obtain the short $\mathrm{Li}^{+}$transport paths and higher energy density of the cell within the same areal footprint.

The electrochemical performance of 3D batteries based on these architectures mostly depends on the achieved aspect ratios (length/width) and geometries of the electrode. The interdigitated architectures consisting of the separate anode and cathode arrays, is perhaps the most easily envisaged design. [162] The short $\mathrm{Li}^{+}$transport paths between electrodes and the increased electrode surface area result in a much lower ohmic resist- 

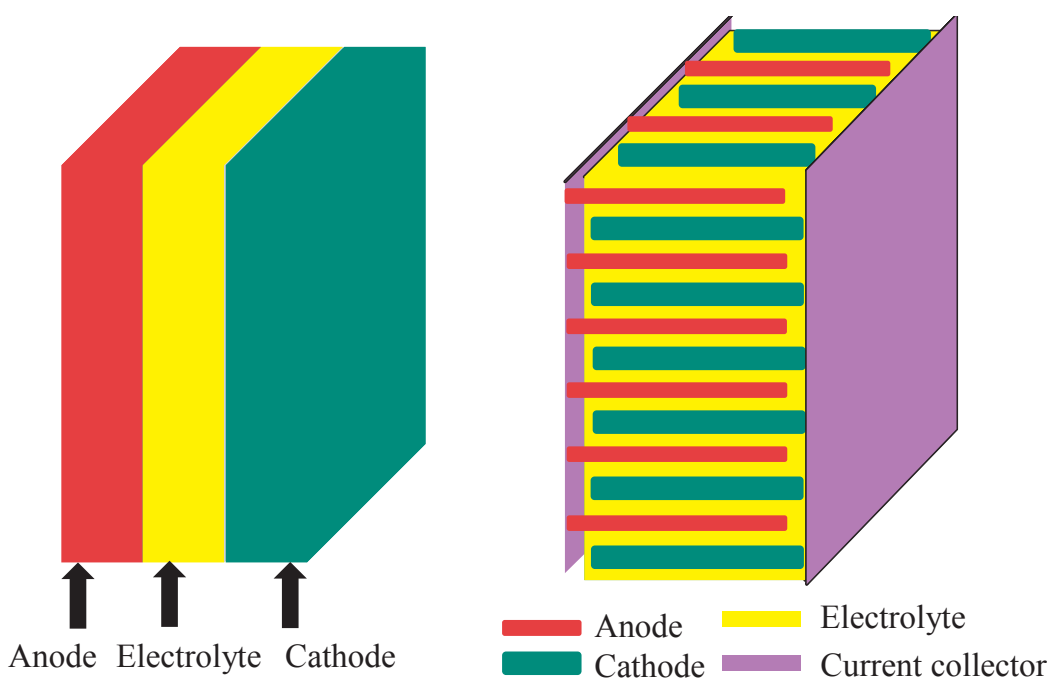

Figure 13. A Schematic illustration of Li-ion microbatteries (a) 2D, parallel thin films and (b) 3D, periodic interdigitated micropillar arrays of anode and cathode are separated by a continuous electrolyte phase.

ance compared to conventional 2D planer counterpart. Initial studies have been carried out on 3D half cell microbatteries consisting of one 3D electrode architecture. One example utilised lithographic methods to amplify the footprint area of 2D thin film battery, essentially by increasing the length (L) of the electrodes to achieve high aspect ratio electrodes. SU-8 negative epoxy based photoresist has been pyrolysed to fabricate high aspect ratio (20:1) C microelectrode arrays following patterning and pyrolysis. [162]

The simplest 3D solid-state battery concept is based on processing of Si substrates to create pillar, figure 14(a) [163] or trench, figure 14(b). [113] In the former case it is difficult to achieve more than 60 micron high features. In addition, sloped sidewalls are desirable to achieve conformal deposition of the active materials using line-of-sight vacuum based deposition processes. Chemical vapour deposition or atomic layer deposition can assist with conformal deposition in higher aspect ratio particularly if thinner layers are required. In this case deep reactive ion etching can create smaller features and thus higher density. Starting from a high surface area Si substrate covered with a current collector, this 3D integrated Li-ion battery concept is based on the successive deposition of diffusion barrier layer of about $70 \mathrm{~nm}$ (Ta, TaN or TiN) followed by a high energy dense Si anode thin film of about $50 \mathrm{~nm}$, a solid-state polymer electrolyte $\mathrm{LiPON}$ of about $1 \mu \mathrm{m}$ and a $\mathrm{LiCoO}_{2}$ thin film of about $1 \mu \mathrm{m}$, and finally deposition of second current collector. The surface area of the battery can be increased 28-fold compared with a 2D planar thin-film battery with the same foot print. The concept appeals widely for powering Si compatible smart autonomous devices in the integrated chip. The difficulty in this processing is the conformal deposition of successive functional layers in such high aspect ratio features and the fact that a considerable proportion of the device volume is electrically and energetically inactive support material. 


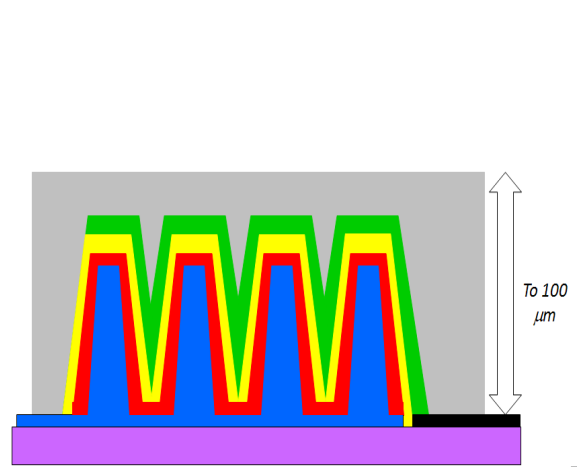

(a)

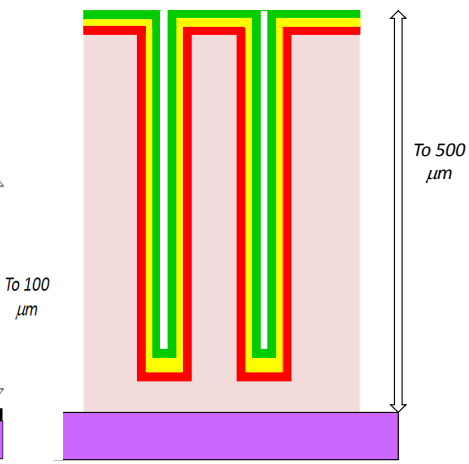

(b)

Figure 14. Schematics of (a) additive trench and (b) deep reactive ion etched structures for 3D microbattery fabrication. In these schematics the active materials are represented by the following colour; red = anode, yellow = electrolyte and green = cathode.

The first fully fabricated and characterised 3D microstructured microbatteries were been demonstrated by Nathan et al [164] for concentric 3D tubule electrode arrays. Templates were fabricated in Si or glass and they have achieved very challenging deposition of the successive active material layers in the high aspect ratio arrays and demonstrated outputs 30 times higher than 2D versions. [165] This 3D microbattery technique based on microchannel plates (MCP) uses conformal thin-films of a Ni cathode current collector, a cathode that is mostly composed of $\mathrm{MoS}_{2}$, a hybrid polymer electrolyte (HPE) and a lithiated MCMB as anode. The cell demonstrated an initial current delivery $2 \mathrm{~mA} / \mathrm{cm}^{2}$, The 3D Li-ion microbatteries retained $60 \%$ of their capacity and $100 \%$ coulombic efficiency after 200 cycles. An issue with trench or pore etched templates acting as substrates for the energy storage device is the volume they occupy which could in the ideal case be composed of active materials thereby increasing the energy storage density of the device. Colloidal processing of materials has been used to process battery materials. [166] 3D electrodes of vanadium oxide nanorolls (VONR) and mesocarbon microbeads (MCMB) can be used as the cathode and anode for Li-ion battery. $[167,168]$ Li tests of 3D VONR and MCMB electrodes fabricated by DRIE combined with colloidal process have been carried out in half cell experiments and the results indicate that $3 \mathrm{D}$ electrode arrays have significantly higher capacity $\left(45 \mu \mathrm{Ah} / \mathrm{mm}^{2}\right)$ than the conventional $2 \mathrm{D}$ thin film version $(6 \mu \mathrm{Ah} /$ $\left.\mathrm{mm}^{2}\right)$. [159]

Template synthesised inverse opal crystal structures can also be the basis for the fabrication of a 3D interpenetrating electrochemical cells. A fully 3D solid-state interpenetrating Li-ion battery has been demonstrated recently [169] in which a photonic crystal templated C anode is coated by a polymer electrolyte (polyethylene oxide) and the remaining void space is filled with a $\mathrm{V}_{2} \mathrm{O}_{5}$ ambigel cathode. The fabrication process addresses some issues faced by $3 \mathrm{D}$ battery designs, for instance, pre-lithiation of the carbon anode and the addition of electrolyte apparently to increase interfacial contacts. Despite these advances, a major remaining barrier to the fabrication of the rechargeable 3D solid-state interpenetrating microbattery is the low 
electronic conductivity of the $\mathrm{V}_{2} \mathrm{O}_{5}$ coupled with the narrow interconnection region between 3D macropores.

Energy storage materials and architectures at the nanoscale is a field of research with many challenges. Some of the design rules and incorporated materials as well as their fabrication strategies have been discussed above. Various 3D architectures and half-cell data has been reported. Optimised full cell versions still requires significant research and development. In particular higher energy density materials with high power performance are required. Matching those capabilities to the available footprint or volume opens up the possibility of a wide range of autonomous microscale devices for future markets. Methods to fabricate and control active materials and architectures at the nanoscale will assist with larger scale versions for improved energy storage in existing markets that require Wh to tens of $\mathrm{kWh}$ storage modules.

\section{Acknowledgements}

This work has been partially funded by EU Framework 7 project Nanofunction, (Beyond CMOS Nanodevices for Adding Functionalities to CMOS) www.Nanofunction.eu EU ICT Network of Excellence, Grant No.257375 and Enterprise Ireland, Project CFTD07325.

\section{Author details}

James F. Rohan, Maksudul Hasan, Sanjay Patil, Declan P. Casey and Tomás Clancy

Tyndall National Institute, University College Cork, Lee Maltings, Cork, Ireland

\section{References}

[1] D. Linden and T.B. Reddy, in Handbook of Batteries, $3^{\text {rd }}$ eds., (2002).

[2] H. Ikeda, T. Saito and M. Tamura, in Proc. Manganese Dioxide Symp. (eds. A. Kozawa and H.R. Brodd) (Cleveland, OH), 1, (1975).

[3] M.S. Whittingham, Science, 192, (1976) 1226.

[4] M.S. Whittingham, Chalcogenide battery, US patent 4009052.

[5] B.M.L. Rao, R.W. Francis and H.A. Christopher, J. Electrochem. Soc., 124, (1977) 1490.

[6] D.W. Murphy, F.J. DiSalvo, J.N. Carides and J.V. Waszczak, Mat. Res. Bull., 13, (1978) 1395. 
[7] M. Lazzari and B. Scrosati, J. Electrochem. Soc., 127, (1980) 773.

[8] J. Broadhead and A.D. Butherus, US patent 3791867.

[9] J. Broadhead, F.J. DiSalvo and F.A. Trumbore, US patent 3864167.

[10] K. Mizushima, P.C. Jones, P.J. Wiseman and J.B. Goodenough, Mat. Res. Bull., 15, (1980) 783.

[11] M.M. Thackeray, W.I.F David, P.G. Bruce and J.B. Goodenough, Mat. Res. Bull., 18, (1983) 461.

[12] S. Basu, US patent 4423125.

[13] M. Mohri, N. Yanagisawa, Y. Tajima, H. Tanaka, T. Mitate, S. Nakajima, Y. Yoshida, Y. Yoshimoto, T. Suzuki, and H. Wada, J. Power Sources, 26, (1989) 545.

[14] T. Nagaura and K. Tozawa, Prog. Batteries Solar Cells, 9, (1990) 209.

[15] M. Armand, J.M. Chabagno and M.J. Duclot, in Fast Ion transport in Solids Electrodes and Electrolytes (eds. P. Vashishta, J.N. Mundy and G.K. Shenoy), North-Holland, Amsterdam, (1979) 131.

[16] K.M. Abraham and M. Alamgir, J. Electrochem. Soc., 137, (1990) 1657.

[17] K.M. Abraham and M. Alamgir, J. Power Sources, 44, (1993) 195.

[18] J.M. Tarascon, A.S. Gozdz, C. Schmutz, F. Shokoohi and P.C. Warren, Solid State Ionics, 86-88, (1996) 49.

[19] Z.X. Shu, R.S. McMillan and J.J. Murray, J. Electrochem. Soc., 140, (1993) 922.

[20] J.M. Tarascon and D. Guyomard, Electrochim. Acta, 38, (1993) 1221.

[21] T. Ohzuku, Y. Iwakoshi and K. Swai, J. Electrochem. Soc., 140, (1993) 2490.

[22] J.R. Dahn, A.K. Sleigh, H. Shi, J.N. Reimers, Q. Zhong and B.M. Way, Electrochim. Acta, 38, (1993) 1179.

[23] N. Sonobe, M. Ishikawa and T. Iwasaki, in Proceedings of the Abstracts of $35^{\text {th }}$ Battery Symposium, Nagoya, Japan, (1994) 47.

[24] T. Takamura, K. Sumiya, J. Suzuki, C. Yamada and K. Sekine, J. Power Sources, 81-82, (1999) 368 .

[25] M. Winter and J.O. Besenhard, Electrochim Acta, 45, (1999) 31.

[26] Anani, S. Crouch-Baker and R.A. Huggins, J. Electrochem. Soc., 134, (1987) 3098.

[27] O. Mao, R.A. Dunlap and J.R. Dahn, J. Electrochem. Soc., 146, (1999) 405.

[28] J.J. Zhang and Y.Y. Xia, J. Electrochem. Soc., 153, (2006) A1466. 
[29] L. Wang, S. Kitamura, K. Obata, S. Tanase and T. Sakai, J. Power Sources, 141, (2005) 286.

[30] H. Mukaibo, T. Momma and T. Osaka, J. Power Sources, 146, (2005) 457.

[31] K.D. Kepler, J.T. Vaughey and M.M. Thackeray, Electrochem. Solid-State Lett., 2, (1999) 307.

[32] H. Li, L. Shi, Q. Wang, L. Chen and X. Huang, Solid State Ionics, 148, (2002) 247.

[33] Y. Idota, T. Kabuto, A. Matsufuji, Y. Maekawa and T. Miyasaki, Science, 276, (1997) 1395.

[34] O. Mao, and J.R. Dahn, J. Electrochem. Soc., 146, (1999) 423.

[35] L.Y. Beaulieu and J.R. Dahn, J. Electrochem. Soc., 147, (2000) 3237.

[36] G.X. Wang, J.H. Ahn, J. Yao, S. Bewlay and H.K. Liu, Electrochem. Commun., 6, (2004) 689.

[37] H. Kim, and J. Cho, J. Electrochem. Soc., 154, (2007) A462.

[38] N. Jayaprakash, N. Kalaiselvi, C. H. Doh, J Appl. Electrochem., 37 (2007) 567

[39] Y. Wang, F. Su, J.Y. Lee and X.S. Zhao, Chem. Mater., 18, (2006) 1347.

[40] X.W. Lou, Y. Wang, C. Yuan. J.Y. Lee and L.A. Archer, Adv. Mater., 18, (2006) 2325.

[41] H. Kim and J. Cho, Chem. Mater., 20, (2008) 1679.

[42] S.W. Kim, M. Kim, W.Y. Lee and T. Hyeon, J. Am. Chem. Soc., 124, (2002) 7642.

[43] M. Yang, J. Ma, C. Zhang, Z. Yang and Y.Lu, Angew. Chem. Int. Ed., 44, (2005) 6727.

[44] J. Gao, B. Zhang, X. Zhang and B. Xu, Angew. Chem. Int. Ed., 45, (2006) 1220.

[45] Y. Wang, J.Y. Lee and H.C. Zeng, Chem. Mater., 17, (2005) 3899.

[46] Y. Wang, H.C. Zeng and J.Y. Lee, Adv. Mater., 18, (2006) 645.

[47] W-M. Zhang, J-S. Hu, Y-G. Guo, S-F. Zheng, L-S. Zhong, W-G. Song and L-J. Wan, Adv. Mater., 20, (2008) 1160.

[48] T. Ohzuku and A. Ueda, Solid State Ionics, 69, (1994) 201.

[49] Y. Gao, M.V. Yakovleva and W.B. Ebner, Electrochem. Solid State Lett., 1, (1998) 117.

[50] C. Pouillerie, F. Perton, P. Biensan, J.P. Peres, M. Broussely and C. Delmas, J. Power Sources, 96, (2001) 293.

[51] C. Pouillerie, L. Croguennec and C. Delmas, Solid State Ionics, 132, (2000) 15.

[52] I. Nakai and T. Nakagome, Electrochem. Solid State Lett., 1, (1998) 259.

[53] M. Brouselly, Lithium Battery Discussion, Bordeaux-Archachon (2001). 
[54] R. Chen and M.S. Whittingham, J. Electrochem. Soc., 144, (1997) L64.

[55] F. Capitaine, P. Gravereau and C. Delmas, Solid State Ionics, 89, (1996) 197.

[56] R. Stoyanova, E. Zhecheva and L. Zarkova, Solid State Ionics, 73, (1994) 233.

[57] K. Numata and S. Yamanaka, Solid State Ionics, 118, (1999) 117.

[58] M.E Spahr, P. Novak, B. Schnyder, O.Haas and R. Nesper, J. Electrochem. Soc., 145, (1998) 1113.

[59] T. Ohzuku and Y. Makimura, Chem. Lett., 8, (2001) 744.

[60] S. Yang, Y. Song, K. Ngala, P.Y. Zavalij and M.S. Whittingham, J. Power Sources, 119, (2003) 239.

[61] Z. Wang, Y. Sun, L. Chen and X. Huang, J. Electrochem. Soc., 151, (2004) A914.

[62] Y.W. Tsai, J.F. Lee, D.G. Liu and B. Hwamg, J. Mater. Chem., 14, (2004) 958.

[63] S.H. Park, C.S. Yoon, S.G. Kang, H-S. Kim, S-I. Moon and Y-K. Sun, Electrochim. Acta, 49, (2004) 557.

[64] N. Yabuuchi and T. Ohzuku, J. Power Sources, 171, (2003) 119.

[65] J.M. Kim and H.T. Chung, Electrochim. Acta, 49, (2004) 937.

[66] S. Jouanneau, D.D. Macneil, Z. Lu, S.D. Beattie, G. Murphy and J.R. Dahn, J. Electrochem. Soc., 150, (2003) A1299.

[67] N. Ravet, Y. Chouinard, J.F. Magnan, S. Besner, M. Gauthier, and M. Armand, J. Power Sources., 97-98, (2001) 503.

[68] H. Huang, S.-C. Yin and J.F. Nazar, Electrochem. Solid-State Lett., 4, (2001) A170.

[69] J.-M. Tarascon and M. Armand, Nature, 541, (2008) 652.

[70] R. Dominko, M.Bele, M. Gaberscek, M. Remskar, D. Hanzel, S. Pejovnik and J. Jamnik, J. Electrochem. Soc., 152, (2005) A607.

[71] R. Dominko, M.Bele, M. Gaberscek, M. Remskar, D. Hanzel, J.M. Goupil, S. Pejovnik and J. Jamnik, Solid State Ionics, 153, (2006) 274.

[72] M. Gaberscek and J. Jamnik, Solid State Ionics, 177, (2006) 2647.

[73] Y.-H Huang, K.-S Park and J.B. Goodenough, J. Electrochem. Soc., 153, (2006) A2282.

[74] Y.-S. Hu, Y.-G. Guo, R. Dominko, M. Gaberscek, J. Jamnik and J. Maier, Adv. Mater., 19 (2007) 1963.

[75] M.S. Whittingham, J. Electrochem. Soc., 123, (1976) 315.

[76] F.W. Dampier, J. Electrochem. Soc., 121, (1974) 656.

[77] R.J. Gummow, A.D. Kock and M.M. Thackeray, Solid State Ionics, 69, (1994) 59. 
[78] C. Delmas, H. C. Auradou, J.M. Cocciantelli, M. Ménétrier and J.P. Doumerc, Solid State Ionics, 69, (1994) 257.

[79] D.W. Murphy, P.A Christian, F.J. Disalvo and J.N. Carides, J. Electrochem. Soc., 126, (1979) 497.

[80] J.O. Besenhard and R. Schöllhorn, J. Power Sources, 1, (1976) 267.

[81] K. Nassau and D.W. Murphy, J. Non-Cryst. Solids, 44, (1981) 297.

[82] P.S. Herle, B. Ellis, N. Coombs and L.F. Nazar, Nat. Mater., 1 (2002) 123.

[83] S.-Y. Chung, J.T. Bloking and Y.-M. Chiang, Nat. Mater., 1 (2002) 123.

[84] Q. Wang, J. Sun, X. Yao and C. Chen, Thermochimica Acta, 437, (2005) 12.

[85] T. Kawamura, A. Kimura, M. Egashira, S. Okada and J.I. Yamaki, J. Power Sources, $104,(2002) 260$.

[86] H. Yang, G. V. Zhuang and P. N. Ross Jr., J. Power Sources, 161, (2006) 573.

[87] S.I. Lee, U.H. Jung, Y.S. Kim, M.H. Kim, D.J. Ahn and H.S. Chun, Korean J. Chem. Eng., 19, (2002) 638.

[88] M. Morita, M. Ishikawa and Y. Matsuda, in Lithium Ion Batteries "Organic electrolytes for rechargeable lithium ion batteries" (eds. M. Wakihara, O. Yamamoto), Kodansha, Tokyo, Wiley/VCH, Weinheim, (1998) 156.

[89] D. Aurbach, A. Zaban, Y. Ein-Eli, I. Weissman, O. Chusid, B. Markovsky, M. Levi, E. Levi, A. Schechter and E. Granot, J. Power Sources, 68, (1997) 91.

[90] S.E Sloop, J.B. Kerr and K. Kinoshita, J. Power Sources, 119-121, (2003) 330.

[91] P. Liu and H. Wu, J. Power Sources, 56, (1995) 81.

[92] M. Arakawa and J. Yamaki, J. Electroanal. Chem., 219, (1987) 273.

[93] M. Alamgir and K.M. Abraham, in Lithium Batteries "New Materials, Developments and Perspectives" (ed. G. Pistoia), Amsterdam, Elsevier, (1994) p 93.

[94] G. Feuillade and P. Perche, J. Appl. Electrochem., 5, (1975) 63.

[95] S. Chintapalli and R. Frech, Solid State Ionics, 86-88, (1996) 341.

[96] E. Tsuchida, H. Ohno and K. Tsunemi, Electrochimica Acta, 28, (1983) 591.

[97] N.S. Mohamed and A.K. Arof, J. Power Sources, 132, (2004) 229.

[98] M. Watanabe, M. Kanba, K. Nagaoka and I. Shinohara, J. Appl. Polym. Sci., 27, (1982) 4191.

[99] G.B. Appetecchi and B. Scrosati, Electrochimica Acta, 43, (1998) 1105.

[100] G.B. Appetecchi, F. Croce and B. Scrosati, Electrochimica Acta, 40, (1995) 991. 
[101] J. Vondrak, M. Sedlarikova, J. Velicka, B. Klapste, V. Novak and J. Reoter, Electrochimica Acta, 46, (2001) 2047.

[102] C. Capiglia, Y. Saito, H. Kataoka, T. Kodama, E. Quartarone and P. Mustarelli, Solid State Ionics, 131, (2001) 291.

[103] D. Saikia and A. Kumar, Electrochimica Acta, 49, (2004) 2581.

[104] F. Croce, F. Gerace, G. Duatzemberg, S. Passerini, G.B. Appetecchi and B. Scrosati, Electrochimica Acta, 39, (1994) 2187.

[105] Z. Jiang, B. Carroll and K.M. Abraham, Electrochimica Acta, 42, (1997) 2667.

[106] A.S. Gozdz, C. Schmutz and J.M. Tarascon, US Patent No 5296318

[107] M.M.E. Jacob, E. Hackett and E.P. Giannelis, J. Mater. Chem., 13, (2003) 1.

[108] S. Abbrent, S.H. Chung, S.G. Greenbaum, J. Muthu and E.P. Giannelis, Electrochimica Acta, 48, (2003) 2113.

[109] M. Wachtler, D. Ostrovskii, P. Jacobsson and B. Scrosati, Electrochimica Acta, 50, (2004) 357.

[110] V. Gentili, S. Panero, P. Reale and B. Scrosati, J. Power Sources, 170, (2007) 185.

[111] Y. Wang, V. Schmidt, S. Senz and U. Gosele, Nat. Nanotechnol., 1, (2006) 189.

[112] J.W. Long, B. Dunn, D.R. Rolison, H.S. White, Chem. Rev. 104 (2004) 4463

[113] L. Baggetto, R.A.H. Niessen, F. Roozeboom, P.H.L. Notten, Adv. Funct. Mater., 18 (2008). 1057

[114] C. R. Sides, C. R. Martin, Nanomaterials in Li-Ion Battery Electrode Design, Modern Aspects of Electrochemistry, no. 40, R. E. White, Editor, p. 75, Springer, New York (2007)

[115] C. R. Martin, Adv. Mater. 3 (1991) 457

[116] J.C. Hulteen and C.R. Martin, J. Mater. Chem., 7, (1997) 1075.

[117] S. A. Sapp, B.B. Lakshmi, C. R. Martin, Adv. Mater. 12 (1999) 402

[118] H. Masuda, K. Fukuda, Science 268 (1995) 1466

[119] S. Shingubara, O. Okino, Y. Sayama, H. Sakaue, T. Takahagi, Solid-State Electronics 43 (1999) 1143

[120] D. Crouse, Y.H. Lo, A.E. Miller, M. Crouse, Appl. Phys. Lett. 76 (2000) 49

[121] N.V. Myung, J. Lim, J-P. Fleurial, M. Yun, W. West, D. Choi, Nanotechnology, 15 (2004) 833

[122] J-H. Kim, S. Khanal, M. Islam, A. Khatri, D. Choi, Electrochem. Commun, 10 (2008) 1688 
[123] F. Cheng, Z. Tao, J. Liang, J. Chen, Chem. Mater. 20 (2008) 667

[124] A.M. Morales and C.M. Lieber, Science, 279, (1998) 208.

[125] C.K. Chan, X.F. Zhang and Y. Cui, Nano Lett., 8, (2008) 307.

[126] N. Zhao, G. Wang, Y. Huang, B. Wang, B. Yao and Y. Wu, Chem. Mater., 20, (2008) 2612.

[127] A.S. Arico, P. Bruce, B. Scrosati, J.-M. Tarascon, W.V. Schalkwijk, Nat. Mater., 4, (2005) 366.

[128] C.K. Chan, H. Peng, R.D. Twesten, K. Jarausch, X.F. Zhang and Y. Cui, Nano Lett., 7, (2007) 490.

[129] J. O. Besenhard, J. Yang and M. Winter, J. Power Sources, 68, (1997) 87.

[130] J.F. Rohan, M. Hasan and N. Holubowitch, Electrochim. Acta, 56 (2011) 9537

[131] D. Larcher, L.Y. Beaulieu, D.D. MacNeil, J.R. Dahn, J. Electrochem. Soc., 147 (2000) 1658.

[132] L. Fransson, E. Nordstrom, K. Edstrom, L. Haggstrom, J.T. Vaughey, M.M. Thackeray, J. Electrochem. Soc. 149 (2002) A736

[133] A.H. Whitehead, J.M. Elliott, J.R. Owen, J. Power Sources 81-82 (1999) 33

[134] J. Graetz, C.C. Ahn, R. Yazami and B. Fultz, J. Electrochem. Soc., 151, (2004) A698.

[135] Y. Wang, X. Jiang and Y. Xia, J. Am. Chem. Soc., 125, (2003) 16176.

[136] N. Ramgir, I. Mulla and K. Vijayamohanan, J. Phys. Chem. B, 108, (2004) 14815.

[137] W. Yu, X. Li, X. Gao and F. Wu, J. Phys. Chem. B, 109, (2005) 17078.

[138] Y. Wang, J.Y. Lee and H.C. Zeng, Chem. Mater., 17, (2005) 3899.

[139] Y. Wang, H.C. Zeng and J.Y. Lee, Adv. Mater., 18, (2006) 645.

[140] P.L. Taberna, S. Mitra, P. Poizot, P. Simon and J.-M. Tarascon, Nature, 5, (2006) 567.

[141] Y. Li, B. Tan and Y. Wu, Nano Lett., 8, (2008) 265.

[142] T. Chowdhury, D.P. Casey and J.F. Rohan, Electrochem. Commun., 11 (2009) 1203

[143] M. Hasan, T. Chowdhury and J.F. Rohan, J. Electrochem. Soc., 157 (2010) A682

[144] C.K. Chan, H. Peng, G. Liu, K.M. Wrath, X.F. Zhang, R.A. Huggins and Y. Cui, Nature, 3, (2008) 31

[145] C.K. Chan J. Power Sources 189 (2009) 34-39

[146] L-F. Cui, R. Ruffo, C.K. Chan, H. Peng, Y. Cui, Nano Lett., 9 (2009) 1

[147] H. Kim and J. Cho, Nano Lett., 8, (2008) 3688. 
[148] C.J. Patrissi and C.R. Martin, J. Electrochem. Soc., 146, (1999) 3176.

[149] C.R. Sides and C.R. Martin, Adv. Mater., 17, (2005) 125.

[150] K. Takahashi, S. J. Limmer, Y. Wang and C.Z. Cao, J. Phys. Chem. B, 108, (2004) 9795.

[151] K. Takahashi, Y. Wang and C.Z. Cao, Appl. Phys. Lett., 86, (2005) O53102.

[152] M.E. Spahr, P. Bitterli, R. Nesper, M. Müller, F. Krumeich and H.U. Nissen, Angew. Chem. Int. Ed., 37, (1998) 1263.

[153] Y. Wang, K. Takahashi, H. Shang and G.Z. Cao, J. Phys. Chem. B, 109, (2005) 3085.

[154] W.C. West, N.V. Myung, J.F. Whitacre and B.V. Ratnakumar, J. Power Sources, 126, (2004) 203.

[155] J.F. Rohan, D.P. Casey, B. Ahern, F.M.F. Rhen, S. Roy, D. Fleming and S.E. Lawrence, Electrochem. Commun, 2008101419

[156] J-Y. Luo, H-M. Xiong and Y-Y. Xia, J. Phys. Chem. C, 112, (2008) 12051.

[157] J. Cho, J. Mater. Chem., 18, (2008) 2257.

[158] S.H. Lim and J. Cho, Electrochem. Commun., 10, (2008) 1478.

[159] X. Li, F. Cheng, B. Guo and J. Chen, J. Phys. Chem. B, 109, (2005) 14017.

[160] S.D. Jones, J.R. Akridge, J. Power Sources 54 (1995) 63

[161] J.B. Bates, N.J. Dudney, D.C. Lubben, G.R. Gruzalski, B.S. Kwak, X. Yu, R.A. Zuhr, J. Power Sources 54 (1995) 58

[162] C. Wang, L. Taherabadi, G. Jia, M. Madou, Y. Yeh and B. Dunn, Electrochem. SolidState Lett. 7, (2004) A435.

[163] A.V. Jeyaseelan and J.F. Rohan, Appl. Surf. Science 256S (2009) S61

[164] M. Nathan, D. Golodnitsky, V. Yufit, E. Strauss, T. Ripenbein, I. Shechtman, S. Menkin and E. Peled, J. MEMS, 14, (2005) 879.

[165] D. Golodnitsky, V. Yufit, M. Nathan, I. Shechtman, T. Ripenbein, E. Strauss, S. Menkin and E. Peled, J. Power Sources, 153, (2006) 281.

[166] J.A. Lewis, J. Amer. Ceram. Soc., 83, (2000) 2341.

[167] D. Sun, C.W. Kwon, G. Baure, E. Richman, J. MacLean, B. Dunn and S.H. Tolbert, Adv. Funct. Mater., 14, (2004) 1197.

[168] J. Yao, G.X. Wang, J.-H. Ahn, H.K. Liu and S.X. Dou, J. Power Sources, 114, (2003) 292.

[169] N.S. Ergang, M.A. Fierke, Z, Wang, W.H. Smyrl and A. Stein, J. Electrochem. Soc., 154, (2007) A1135. 